\title{
Mechanisms, Pathophysiology and Currently Proposed Treatments of Chronic Obstructive Pulmonary Disease
}

\author{
Sarah de Oliveira Rodrigues 1,2,3, Carolina Medina Coeli da Cunha ${ }^{2}$, Giovanna Martins Valladão Soares ${ }^{2}$, \\ Pedro Leme Silva ${ }^{4}$, Adriana Ribeiro Silva ${ }^{1,3,5, *,+}$ and Cassiano Felippe Gonçalves-de-Albuquerque ${ }^{1,2,3,6, *,+(\mathbb{D})}$ \\ 1 Laboratório de Imunofarmacologia, Fundação Oswaldo Cruz (FIOCRUZ), Rio de Janeiro 21040-900, Brazil; \\ sarahrodrigues.bio@gmail.com \\ 2 Laboratório de Imunofarmacologia, Departamento de Bioquímica, Instituto Biomédico, Universidade Federal \\ do Estado do Rio de Janeiro, Rio de Janeiro 20211-010, Brazil; carolina.cunha230@gmail.com (C.M.C.d.C.); \\ giovanna_ciccone@hotmail.com (G.M.V.S.) \\ 3 Programa de Pós-Graduação em Ciências e Biotecnologia, Universidade Federal Fluminense, \\ Rio de Janeiro 24020-140, Brazil \\ 4 Laboratório de Investigação Pulmonar, Carlos Chagas Filho, Instituto de Biofísica, Universidade Federal do \\ Rio de Janeiro, Rio de Janeiro 21941-902, Brazil; pedroleme@biof.ufrj.br \\ 5 Programa de Pós-Graduação em Biologia Celular e Molecular, Instituto Oswaldo Cruz (FIOCRUZ), \\ Rio de Janeiro 21040-900, Brazil \\ 6 Programa de Pós-Graduação em Biologia Molecular e Celular, Universidade Federal do Estado do Rio de \\ Janeiro, Rio de Janeiro 20210-010, Brazil \\ * Correspondence: arsilva71@gmail.com (A.R.S.); cassiano.albuquerque@unirio.br (C.F.G.-d.-A.) \\ + Both authors equally contribute to this work.
}

Citation: Rodrigues, S.d.O.; Cunha, C.M.C.d.; Soares, G.M.V.; Silva, P.L.; Silva, A.R.;

Gonçalves-de-Albuquerque, C.F. Mechanisms, Pathophysiology and Currently Proposed Treatments of Chronic Obstructive Pulmonary Disease. Pharmaceuticals 2021, 14, 979. https://doi.org/10.3390/ph14100979

Academic Editors:

Nektarios Barabutis and

Dhimant Desai

Received: 19 March 2021

Accepted: 28 August 2021

Published: 26 September 2021

Publisher's Note: MDPI stays neutral with regard to jurisdictional claims in published maps and institutional affiliations.

Copyright: (c) 2021 by the authors. Licensee MDPI, Basel, Switzerland. This article is an open access article distributed under the terms and conditions of the Creative Commons Attribution (CC BY) license (https:// creativecommons.org/licenses/by/ $4.0 /)$.
Abstract: Chronic obstructive pulmonary disease (COPD) is one of the leading global causes of morbidity and mortality. A hallmark of COPD is progressive airflow obstruction primarily caused by cigarette smoke (CS). CS exposure causes an imbalance favoring pro- over antioxidants (oxidative stress), leading to transcription factor activation and increased expression of inflammatory mediators and proteases. Different cell types, including macrophages, epithelial cells, neutrophils, and T lymphocytes, contribute to COPD pathophysiology. Alteration in cell functions results in the generation of an oxidative and inflammatory microenvironment, which contributes to disease progression. Current treatments include inhaled corticosteroids and bronchodilator therapy. However, these therapies do not effectively halt disease progression. Due to the complexity of its pathophysiology, and the risk of exacerbating symptoms with existing therapies, other specific and effective treatment options are required. Therapies directly or indirectly targeting the oxidative imbalance may be promising alternatives. This review briefly discusses COPD pathophysiology, and provides an update on the development and clinical testing of novel COPD treatments.

Keywords: chronic obstructive pulmonary dysfunction; COPD; pathophysiology; current treatments

\section{Introduction}

A hallmark of chronic obstructive pulmonary disease (COPD) is the chronic obstruction of the airways. COPD is a progressive condition caused by inhalation of toxic particles or gases $[1,2]$. Tobacco smoking and inhalation of other pollutants are the leading causes of COPD [3-5].

COPD is a major cause of global morbidity and mortality, resulting in increased economic and social burden $[1,2,6]$. Variance among countries and between different groups in the prevalence of this disease is often directly related to smoking prevalence, although environmental pollution is also a significant risk factor in many countries. The prevalence and burden of COPD will increase in the coming decades due to continued exposure to risk factors and aging of the world population [5,7]. There are many pulmonary and systemic comorbidities in COPD patients, such as bronchiectasis, asthma, heart failure, cardiovascular diseases, sleep apnea, malnutrition, and frailty [8]. 
The inflammatory process can alter the bronchi, bronchioles, and pulmonary parenchyma, leading to progressive restriction of airflow, resulting in emphysema and chronic bronchitis $[9,10]$. The pathogenesis of emphysema includes destruction of alveolar septa, increased air space, and loss of elastic recoil due to hyperinflammation and oxidative stress [11-13]. Chronic bronchitis involves the overproduction and hypersecretion of mucus by goblet cells, thereby reducing airflow [14] (Figure 1).
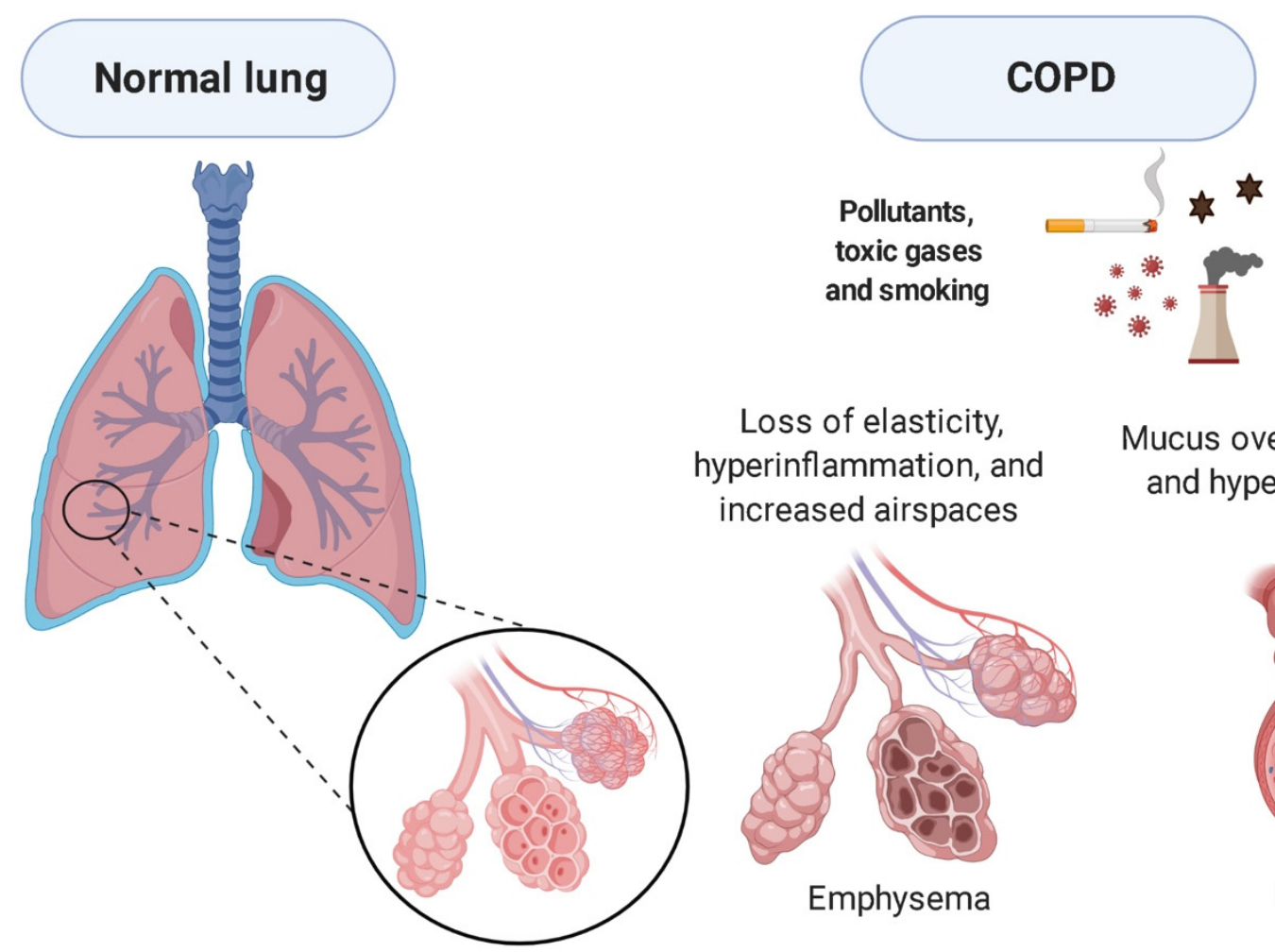
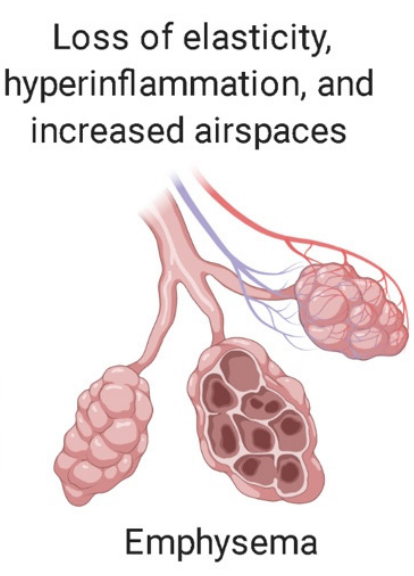

\section{Mucus overproduction and hypersecretion}

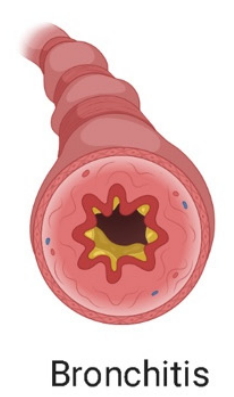

Figure 1. COPD phenotypes. Morphological differences exist between a normal lung and a lung with COPD. In addition, lungs with COPD can present two different characteristics: emphysema, which promotes alveolar destruction and consequent reduction in lung function, and bronchitis, which increases mucus production, narrowing airways and reducing air flow. Created with BioRender.com.

\section{Epidemiology}

COPD was estimated to affect 251 million people in 2016, and in 2015, 3.17 million patients worldwide died due to COPD, ranking COPD as the third most deadly disease [15]. The highest prevalence occurs in the Americas [16,17], where its prevalence has increased over the past 20 years. Despite the growing global burden, COPD is neglected in lowincome countries, where it is considered a non-communicable disease $[18,19]$. In Canada, the risk of developing COPD is similar to that of developing diabetes, which is more significant than the risk of developing congestive heart failure [20].

According to the Centers for Disease Control and Prevention, the United States had 153,445 deaths due to COPD in 2019. In 2018, 5.1\% of adults (approximately 12.8 million people) were diagnosed with COPD [21,22]. COPD prevalence is higher in women than in men, increasing exponentially with age. Race/ethnicity and socioeconomic status are also risk factors $[23,24]$.

In 2010, most COPD-related deaths occurred in low- and middle-income countries. No population-based epidemiological studies have been conducted in these countries [25]. In developing countries, exposure to biomass can be a risk factor for non-smoking related COPD, impacting strategies for prevention and treatment [26]. Studies have also shown evidence supporting a relationship between air pollution and COPD [27]. Hence, COPD prevalence is generally higher than health authorities' estimates, rendering it an under- 
diagnosed disease. There are several reasons for this underestimation, including lack of robust diagnostic standards, variation in lung function tests, inconsistent use of COPD terminology, and limited government funding $[25,28,29]$. The disease COVID-19 caused by the Severe Acute Respiratory Syndrome Coronavirus 2 (SARS-CoV-2) was declared pandemic by the WHO in March 2020, and since then, it has continued to spread, mainly in elderly people and people with comorbidities. Diabetes, obesity, cardiovascular diseases, and respiratory diseases are among the comorbidities linked to increased severity in cases of COVID-19 [30]. Data relating COPD and COVID-19 are contradictory, with the incidence of COVID-19 in COPD patients being lower than expected. The reason for this is unclear [31]. However, it is essential to highlight that patients with COPD are at increased risk of developing severe COVID-19 [32].

\section{Pathophysiology}

In normal alveolar septa, elastic fibers located subepithelial layer are predominant, which confer resistance to connective tissue, allowing deformability and passive recoil without energy input [33]. Elastic fibers are mechanically connected to collagen fibers via microfibrils and/or proteoglycans [34,35]. Traditionally, elastic fibers are responsible for lung elasticity within a normal lung volume range, while collagen fibers are responsible to halt lung volume when it approaches the total lung capacity [35].

The breakdown of elastic fibers, so-called elastolysis, is one of the hallmarks of emphysema, an important phenotype contributing to COPD [36]. COPD is characterized by progressive airflow limitation that is not fully reversible, associated with an abnormal inflammatory response of the lungs to noxious particles or gases [2,37]. Emphysema is the result of destruction of alveolar walls, which leads to reduced gas exchange, permanent airspace enlargement, loss of elastic recoil, hyperinflation, and expiratory flow limitation [38-40]. As a consequence of fiber destruction by metalloproteinases, there are changes in collagen- and elastic-fiber organization [11]. These features affect the lung's tissue stability and mechanical properties, contributing to lung function decline overtime and accelerating disease progression [41,42].

\subsection{Diaphragm Dysfunction and COPD}

The dynamics hyperinflation results in diaphragm mechanical disadvantage leading to dysfunction $[43,44]$. Clinical studies using ultrasonography in in-hospital patients have shown its ability to detect diaphragm weakness, resulting in increased hospital length of stay $[45,46]$. The diaphragm weakness acquired during exacerbation can be explained by: (1) elevated number of inflammatory cells in the lungs [47,48]; (2) oxidative stress and damage within the diaphragm [49]; (3) diaphragm remodeling [44]; (4) maintenance of hyperinflated areas, which jeopardize diaphragm performance [50,51]; and (5) changes in mitochondrial dynamics. Several studies have shown that mitochondria are dynamic organelles with the ability to change morphology and function according to the pathologic situations through fusion and fission processes [52]. Mitochondrial fusion is mediated by proteins located at the external mitochondria membrane, such as mitofusin 1 (MFN1), mitofusin 2 (MFN2), and optic protein factor 1 (OPA 1). These proteins hydrolases GTP and promote mitochondria fusion, which allows DNA, protein, and metabolites sharing. Mitofusins act toward the external membrane forming homo- and heterodimers [53,54], while OPA1 acts toward the internal membrane. Thus, the loss of these proteins may lead to mitochondrial DNA damage [55], affecting bioenergetics function [56]. The mitochondrial fission is characterized by mitochondria fragmentation, and the main objectives are: (1) to increase the mitochondria numbers to distribute to new cells during mitosis [57]; (2) to transport to other regions of the cell; and (3) to signalize injured cells and forward them to mitophagy [58] and apoptosis. First, fission occurs through the inhibition of mitochondrial fusion protein. Second, the fission process demands the presence of mitochondrial fission, such as dynamin-related protein 1 (DRP1) [59], which interacts with human fission factor (Fis 1) and mitochondria fission factor (MFF). Thus, the extensive activation of DRP1 may 
increase mitochondrial fragmentation, increasing reactive oxygen species followed by decreased ATP production [60,61].

\subsection{Pulmonary Arterial Hypertension and COPD}

Pulmonary arterial hypertension (PAH) and diaphragm dysfunction are commonly observed during COPD progression, contributing to exacerbations [62,63]. Exacerbations are acute episodes caused by viral and bacterial infections, which worsen airway inflammation, cause lung function decline followed by hospitalization, and increase mortality $[64,65]$. COPD patients who present PAH have decreased survival rate compared to COPD patients at similar severity but without PAH [62]. One probable explanation is that PAH is associated with vascular remodeling, likely due to collagen fibers accumulation beneath pulmonary vessels, which leads to vessel narrowing overloading the right ventricle [66-68]. Furthermore, during PAH associated with COPD development, there is an increase in the pulmonary inflammatory process and the release of vasoactive agents, such as thromboxane A2. It can induce vascular constriction and further increase vascular resistance [69].

\subsection{Reactive Oxygen Species and COPD}

In addition to inflammation, COPD is characterized by an imbalance between proteases and their inhibitors, oxidative stress, and infections that generate disease symptoms [70,71]. Prognosis for COPD patients depends on different factors, including disease severity, body mass index, and age [10]. Patients display increased numbers of neutrophils, macrophages, and $\mathrm{T}$ cells in the lungs, increasing chemotactic mediators [71]. In addition to pulmonary inflammation, there is also systemic inflammation with increased levels of fibrinogen, C-reactive protein (CRP), serum amyloid A (SAA), and pro-inflammatory cytokines tumor necrosis factor-alpha (TNF- $\alpha$ ), interleukin-6 (IL-6), and IL-8 in the serum [72]. Cigarette smoke (CS) is the primary source of oxidant agents in the lungs, but inflammatory cells and phagocytes residing in the respiratory tract also generate reactive oxygen species (ROS) in the lungs [70,73]. Increased nicotinamide adenine dinucleotide phosphate (NADPH) activity in epithelial cells, phagocytes, and myeloperoxidase in neutrophils is responsible for ROS production in patients with COPD [73]. Oxidative stress generated by $\mathrm{CS}$ results in nuclear kappa $\mathrm{B}(\mathrm{NF}-\mathrm{kB})$ activation, producing inflammatory mediators that foster tissue damage $[70,73]$. NF- $\kappa B$ activation induces cytokines, chemokines, and cell adhesion molecules, which are boosted by bacterial or viral infections, exacerbating disease symptoms [74]. Oxidative stress is the primary cause of COPD pathogenesis, triggering apoptosis, extracellular matrix remodeling, inactivation of protease inhibitors, mucus secretion, NF- $\mathrm{kB}$ activation, mitogen-activated protein kinase (MAPK) activation, chromatin remodeling, and pro-inflammatory gene transcription [71,74,75].

Healthy lungs possess enzymatic and non-enzymatic antioxidant mechanisms that counteract oxidative stress. Non-enzymatic mechanisms involve glutathione (GSH), vitamin C, uric acid, vitamin E, and albumin. Enzymatic mechanisms rely on superoxide dismutase (SOD), catalase, and glutathione peroxidase (Gpx) [72]. Exposure to CS decreases intracellular GSH levels, boosting oxidative stress in COPD patients [76]. The transcription factor nuclear factor erythroid 2-related factor 2 (Nrf2) is crucial for regulating the cellular antioxidant response and preventing ROS-induced injury. Nrf2 regulates the expression of genes encoding enzymes that regulate oxidative stress, including the typical phase 2 detoxifying enzyme hemoxygenase-1 (HO-1). Decreased Nrf2 pathway stimulation in peripheral lung tissue and alveolar macrophages is associated with increased susceptibility to and severity of COPD [77].

In the next section, we discuss both immune and structural cells in COPD pathophysiology.

\section{Inflammatory Cells and Mediators}

The terminal bronchioles and lung parenchyma are the main regions affected by COPD inflammation, and are characterized by infiltrating macrophages and CD8 $8^{+} \mathrm{T}-$ cells. Macrophages are primarily present within the lungs, while $\mathrm{CD}^{+} \mathrm{T}$-cells cause 
alveolar epithelial cell apoptosis and destruction through release of perforins and TNF$\alpha$ [9]. Macrophages and neutrophils are involved in ROS generation during COPD [70]. In response to macrophages and neutrophils, alveolar epithelial cells release leukotriene B4 (LTB4), a chemotactic factor that attracts immune cells $[9,78]$. Macrophages and pulmonary cells also produce IL-8/CXCL8 [79] and growth-related oncogene (GRO $\alpha$ )/CXCL1, which amplify the inflammatory response by attracting more leukocytes from the blood to the inflammatory site [80]. Patients with COPD display smoking-linked ICAM-1 augmentation in epithelial cells. ICAM-1 is an adhesion molecule that is crucial for leukocyte migration. It is highly expressed in patients with severely limited airflow, and is associated with increased risk of viral and bacterial infections [81].

The imbalance between proteases and their inhibitors plays a crucial role in COPD pathogenesis. Proteases, including neutrophil elastase (NE) and proteinase 3, degrade connective tissue components, especially elastin, leading to emphysema $[78,82]$. Elastin is detected in the serum of patients with COPD due to massive tissue destruction [82]. $\alpha 1$-antitrypsin can inhibit NE, but it is reductively inactivated in COPD patients [83]. Elastic fiber damage may lead to collagen deposition in the pulmonary parenchyma, leading to alveolar septa destruction and alveolar distention [3]. Metalloproteinases (MMPs) attack the extracellular matrix, causing the release of elastin fragments that attract monocytes to the lungs. MMPs are also involved in recruiting pulmonary macrophages, thus raising proteolytic and inflammatory activity, thereby playing an essential role in COPD progression [11].

NE regulates expression of the $M U C 5 A C$ gene, which encodes the gel-forming mucin of the respiratory tract, through an ROS-dependent mechanism [70] associated with airway obstruction and disease severity [84-87]. Bacterial components, such as lipopolysaccharide (LPS), and cytokines, such as IL-9, TNF- $\alpha$, and IL-1 $\beta$, enhance MUC5AC gene expression $[70,79]$, amplifying the inflammatory process.

Therefore, ROS, inflammatory mediators, and proteolytic enzyme production can initiate, enhance, and aggravate tissue damage, and exacerbate lung injury, resulting in COPD development and progression (Figure 2).

\subsection{Alveolar Epithelial Cells}

Alveolar epithelial cells serve as a mechanical barrier to harmful stimuli [88]. Exposure of these cells to CS and other pollutants activates several intracellular signaling pathways, which induce pro-inflammatory mediators, including CXCL8/IL-8, GM-CSF, ICAM-1, and TNF- $\alpha$, regulating the influx of inflammatory cells [89].

Vascular endothelial growth factor (VEGF) and hepatocyte growth factor (HGF) are vital for maintaining alveolar epithelial cell integrity [90]. Low VEGF and HGF levels have been associated with alveolar epithelial cell apoptosis in COPD patients [91]. After exposure to inhaled irritants, small airway epithelial cells increase TGF- $\beta$ expression, which stimulates fibroblasts to differentiate into myofibroblasts that produce extracellular matrix (ECM), leading to local fibrosis [92]. While MMP-9 is released by cells involved in immune defense, such as macrophages, MMP- 2 is synthesized by fibroblasts, and has been associated with chronic tissue remodeling, leading to abnormal tissue changes [93]. Furthermore, intense ROS production can disrupt surfactant secretion by alveolar epithelial cells, leading to alveolar collapse and high airway resistance due to interdependence, a typical sign of emphysema [89,94].

ROS production is also associated with mitochondrial DNA damage, causing mitochondrial dysfunction [95]. Such dysfunction has been reported in airway smooth muscle cells in COPD patients [96]. CS inhibits mitochondrial respiratory function, reducing ATP production, which induces mitophagy in alveolar epithelial cells [97]. Mitochondrial ROS generation has been associated with surfactant changes, thus interfering with alveolar epithelial cell stability [98].

Inhaled toxic agents damage alveolar epithelial cells, causing the release of damageassociated molecular patterns (DAMPs), observed in bronchoalveolar lavage fluid (BALF) 
from COPD patients [99]. CS induces alterations in alveolar epithelial cells, leading to alveolar-capillary barrier dysfunction [100]. Damage to alveolar capillaries facilitates pathogen entrance, increasing the risk of exacerbating symptoms [101].

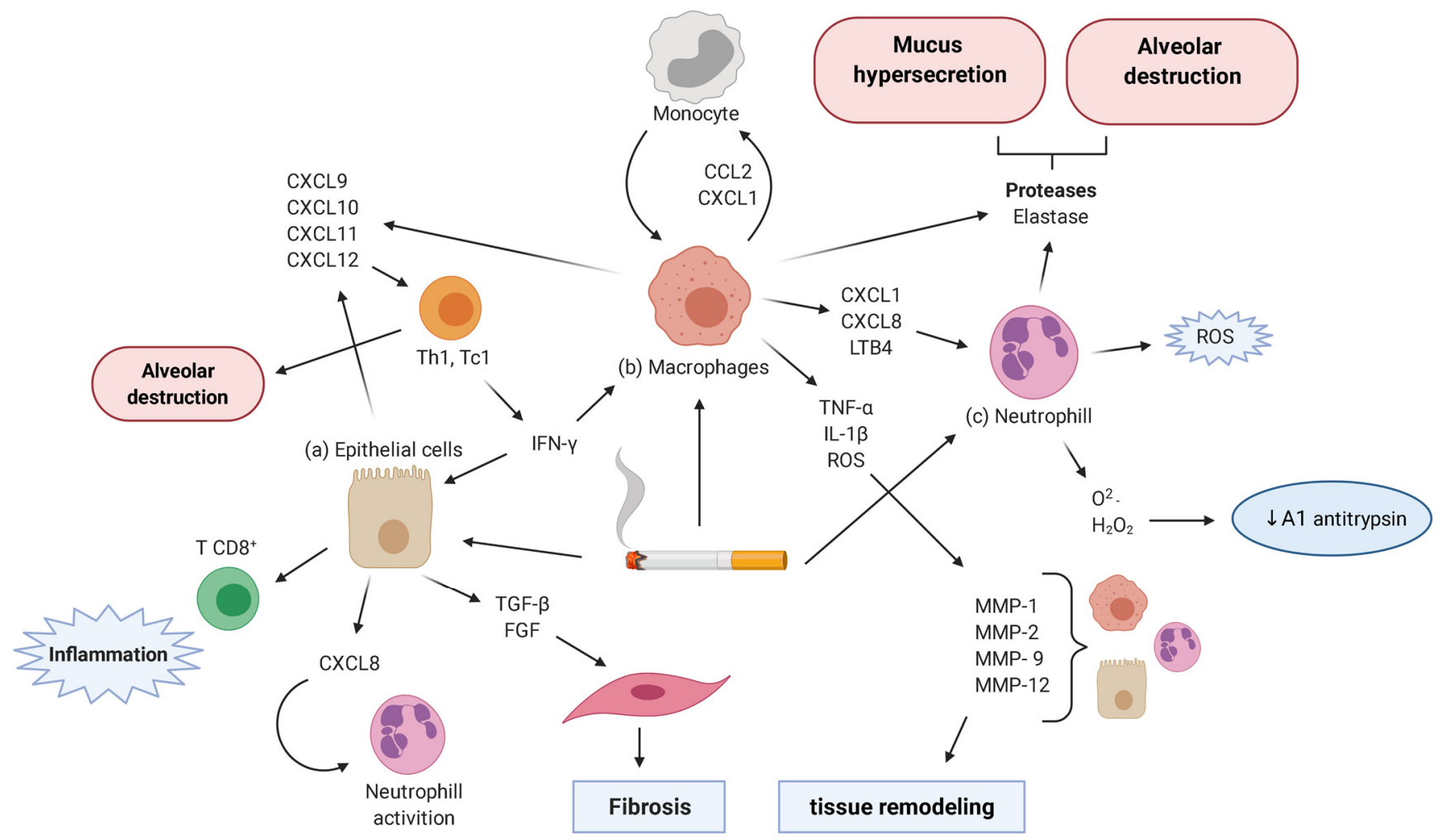

Figure 2. COPD pathophysiology. The toxins present in cigarette smoke lead to the recruitment of inflammatory cells and the release of inflammatory mediators. Macrophages release CXCL1, CXCL8, and LTB4, which attract neutrophils, and CCL2 and CXCL1, which attract monocytes. Neutrophils release ROS, enhancing inflammation and reductively inactivating $\alpha 1$ antitrypsin. They also release proteases, such as NE, leading to tissue damage. Epithelial cells and macrophages release CXCL9, CXCL10, CXCL11, and CXCL12, which attract Th1 and Tc1 lymphocytes. They also release IFN- $\gamma$, leading to alveolar destruction. Epithelial cells release CXCL8, recruiting and activating neutrophils, and TGF- $\beta$ and FGF, recruiting fibroblasts that promote tissue fibrosis. Epithelial cells also attract $\mathrm{CD} 8^{+} \mathrm{T}$ cells believed to foster inflammation. Macrophages release TNF- $\alpha, \mathrm{IL}-1 \beta$, and ROS, inducing MMP secretion by epithelial cells, macrophages, and neutrophils, causing tissue remodeling. CXCL1, chemokine (C-X-C motif) ligand 1; LTB4, leukotriene B4; CC, Chemokine (C-C motif); IFN $\gamma$, interferon gamma; TGF, transforming growth factor; FGF, fibroblast growth factor; TNF- $\alpha$, tumor necrosis factor alpha; IL, interleukins; ROS, reactive oxygen species; MMPs, metalloproteinases. Created with BioRender.com.

\subsection{Goblet Cells}

Goblet cells are essential to the immune system because of their ability to secrete mucus, antioxidants, protease inhibitors, and defensins, to maintain the epithelial barrier against infectious agents [90]. The epidermal growth factor receptor (EGFR) induces cell proliferation by promoting production of transforming growth factor-alpha (TGF- $\alpha$ ), resulting in mucus production [102,103]. EGFR activation is increased in COPD patients [104], elevating their cell proliferation and mucus production [14]. COPD patients display high production of intracellular mucin, mainly MUC5AC [105], and high NF-kB activation and cytokine release [106]. CS and ROS also amplified MUC5AC expression via EGFR activation. MUC5AC production leads to respiratory tract hypertrophy and hyperplasia [70], facilitating disease progression [107]. Mucus hypersecretion also increases viscosity, decreases antibacterial molecule production, aggravates airflow restrictions, and increases the risk of lung infections [108]. 


\subsection{Alveolar Macrophages}

Alveolar macrophages play a crucial role in innate and adaptive immune responses. They are involved in capturing and processing inhaled harmful agents, and stimulating the immune response by releasing inflammatory mediators, including TNF- $\alpha$, CXCL1, CXCL8, CXCL9, CXCL10, CCL2, leukotriene B4 (LTB4), and ROS [90]. These mediators also recruit monocytes, neutrophils, and lymphocytes to the inflammatory site. Macrophages also secrete elastolytic enzymes, including MMPs and cathepsins [109]. Similar to neutrophils, macrophages generate ROS through NADPH oxidase (NOX) when stimulated by CS oxidants [110]. In functional NOX2-deficient mice, decreased ROS production provided protection against emphysema [111].

Macrophages can be polarized into either M1 or M2. M1 macrophages display classic activation and have a more inflammatory profile, secreting pro-inflammatory cytokines [112]. They are potent effector cells that specialize in killing microorganisms [113]. M2 macrophages are considered less inflammatory, due to their release of anti-inflammatory cytokines, such as IL-10, and participate in tissue remodeling and repair [114]. In COPD, type M1 is more prevalent than M2, indicating a more accentuated inflammatory response [115], denoted by the release of pro-inflammatory mediators including CCL2 and CXCL1, which enhance cell recruitment, and explaining the higher number of macrophages found in the pulmonary parenchyma, BALF, and sputum of COPD patients $[90,116]$. Despite their high numbers, macrophages in COPD have low phagocytic and efferocytotic abilities [117]. This altered behavior is associated with exogenous ROS-induced oxidative stress, which is also responsible for altering mitochondrial function, resulting in uncontrolled ROS production [118]. An inadequate macrophage response favors bacterial infection, with increased risk of developing pneumonia and exacerbated symptoms. Therefore, the decrease in phagocytic and efferocytotic functions is related to COPD progression [119]. Macrophage dysfunction is linked to oxidative stress caused by ROS [120]. In healthy individuals, upon oxidative stress, Nrf2 activates a cellular antioxidant response, but Nrf2 activation in macrophages of COPD patients is attenuated [77].

The increase in elastolytic enzymes, such as MMPs, induces ECM degradation and alveolar wall destruction [121]. Alveolar macrophages are pivotal to COPD development, because even after smoking cessation, their dysfunction may continue to contribute to disease progression [122]. These cells play a primary role in the pathology of COPD, and the integrity of their functions is directly related to the degree of inflammation and disease severity.

\subsection{Lymphocytes}

Lymphocytes can cause alveolar destruction in patients with COPD [123]. Lymphocyteactivating IL-17 and IL-22 levels are increased in patients with COPD [124]. CD8 ${ }^{+}$cells produce pro-inflammatory cytokines, including IL-2, gamma interferon (IFN $\gamma$ ), and TNF $\alpha$, and chemokines, including CXCL10 and CCL5, which recruit other inflammatory cells [125]. All these mediators increase in COPD patients [126], taking part in COPD pathogenesis and autoimmune response [127]. $\mathrm{CD}^{+}$cells release perforins, granzyme $\mathrm{B}$, and TNF$\alpha$, causing cytolysis and apoptosis of alveolar epithelial cells, resulting in emphysema development [128].

$\mathrm{CD} 4 / \mathrm{CD} 28^{\text {null }} \mathrm{T}$ cells are a pro-inflammatory subset of $\mathrm{T}$ helper lymphocytes, whose main characteristic is loss of CD28, a necessary co-stimulatory receptor for CD4+ T cell activation, proliferation, and survival [129]. The increase in these T cells in COPD patients is linked to impaired lung function. Chronic exposure to CS causes a reduction in the costimulatory molecule CD28, increasing expression of perforin, granzyme B, and receptors in NK cells and T cells [130]. COPD patients are resistant to immunosuppression induced by corticosteroids compared to control individuals with higher counts of CD8/CD28 T cells [131]. $\mathrm{T}$ cell senescence in COPD patients may be associated with reduced histone deacetylase 2 (HDAC2) expression in CD8/CD28 $8^{\text {null }} \mathrm{T}$ cells [132]. T cell receptor downregulation leads to 
an inadequate response to infection, causing either autoimmune disease [133] or increased susceptibility to COPD complications [125].

Regulatory T cells (Tregs) cause immune suppression at the inflammatory site, producing IL-10 and TGF- $\beta 1$ [134]. FOXP3 is considered a specific marker of Treg cells [135]. In COPD patients, increased levels of Tregs have a pronounced effect, disrupting effector T cell response and tolerance to self-antigens [136].

Patients with severe COPD have a higher number of B cells in their small airways [137]. They also have higher levels of B cell activation factors in lymphoid follicles [138], and B cells secrete autoantibodies against carbonylated proteins, which form due to oxidative stress [139]. Antibodies against elastin, observed in patients with emphysema, were the first evidence of a relationship between autoimmunity and COPD [140]. COPD patients also present with high levels of anti-endothelial and anti-epithelial antibodies [141]. Similar to rheumatoid arthritis patients, they have citrullinated proteins in the lungs, which can induce autoantibodies [142]. Furthermore, COPD patients display a high percentage of apoptotic cells in follicles, suggesting immune dysfunction [143].

Interestingly, the increased number of neutrophils and B lymphocytes correlates with disease severity [144-146]. Lymphocytes play an essential role in the autoimmune effects in COPD patients. The ratio of neutrophils to lymphocytes has been suggested for use as a prognostic marker for predicting exacerbations in COPD patients $[147,148]$

\subsection{Neutrophils}

COPD patients have increased neutrophil numbers in sputum and BALF [149]. Smoking stimulates the release of granulocytes from the bone marrow and their survival in the respiratory tract [150]. Chemotactic factors, including LTB4, CXCL1, CXCL5, and CXCL8 derived from alveolar macrophages, epithelial cells, and $\mathrm{T}$ cells, can boost neutrophil migration in COPD patients [90].

Expression of adhesion molecules such as E-selectin is increased in COPD patients. E-selectin is expressed on endothelial cells and is critical for neutrophil recruitment [151]. Likewise, myeloperoxidase (MPO) and human neutrophilic lipocalin (HNL) are high in the airways of COPD patients [152]. Upon arrival into the lung inflammation site, activated neutrophils secrete serine proteases (including neutrophil elastase (NE)), cathepsin G, protein-3, MMP-8, and MMP-9, causing alveolar damage [90,153]. Neutrophils also produce neutrophil extracellular traps (NETs), increasing lung tissue damage in COPD patients [154,155].

Although neutrophils may secrete ROS as a defense mechanism in COPD patients, ROS production exceeds physiological levels $[156,157]$. Excess ROS can alter neutrophil migratory patterns [158], activate granular proteases, induce NET formation [159], and inactivate alpha-1-antitrypsin ( $\alpha 1 \mathrm{AT})$, which in turn promotes inflammation [160].

Neutrophil gelatinase-associated lipocalin (NGAL) has been suggested as a systemic marker for COPD [161] because its levels are high in induced sputum and bronchiolar lavage fluid from COPD patients [162]. NGAL is secreted by neutrophils and other cells and possesses antimicrobial properties that can reduce bacterial growth. However, when bound to MMP-9, NGAL extends MMP9 enzyme activity, promoting tissue destruction [163]. Granulocyte-colony-stimulating factor (G-CSF) stimulates neutrophil production in the bone marrow, and promotes their survival, priming, and function. Neutralization, inactivation, or blocking of G-CSF causes inflammation and tissue damage, controls monocyte influx into the lungs, initiates neutrophil apoptosis, and mitigates COPD symptoms $[164,165]$. Neutrophil-mediated inflammation is critical for COPD development and progression [166]. Studies investigating neutrophil infiltration and activity may shed light on the role of these cells in COPD pathogenesis.

\section{Genetic and Epigenetic Regulation}

CS and oxidative stress cause alterations in histones, including acetylation/deacetylation and methylation/demethylation patterns, resulting in DNA damage, cellular senescence, 
and pulmonary cell apoptosis, in addition to pro-inflammatory gene expression [167]. Studies have shown that DNA double-strand breaks (DSBs) are among the most lethal forms of DNA damage caused by smoking and oxidative stress. If not repaired, they cause cellular senescence and apoptosis [168]. Oxidant enzyme encoding genes, including cytochrome P450 family 2 subfamily C member 18 (CYP2C18) and aryl hydrocarbon receptor nuclear translocator-like 2 (ARNTL2), are upregulated in COPD. Other antioxidant genes may undergo mutations, including polymorphisms in glutathione S-transferase (GST) $M 1$, glutathione S-transferase pi 1 (GSTP1), superoxide dismutase 3 (SOD3), and epoxide hydrolase 1 (EPHX1), being related to lowering lung function and COPD severity [70]. Furthermore, the correlation between epigenetics and the production of inflammatory cytokines may also be linked to disease progression [169].

HDACs play a vital role in regulating the inflammatory response. HDACs downregulate oxidative stress sensitive inflammatory gene expression [170]. Macrophage accumulation in the lungs of COPD patients increases the secretion of inflammatory mediators and elastolytic enzymes due to NF-KB activation [171] and the reduction of HDAC2 activity [172]. HDAC2 activity is reduced in alveolar macrophages and lung tissue in COPD patients [77], and this reduced activity is linked to increased histone acetylation at the IL-8 promoter (FISCHER; VOYNOW; GHIO, 2015). CS, oxidative stress, nitrative stress, and aldehyde reduce HDAC2 expression in the lungs [167,173]. Decreased HDAC2 in the lungs further impairs Nrf2 activation, decreasing its half-life, impairing its orchestrated antioxidant defense $[70,174]$, and increasing NF-KB RelA/p65 subunit activation, and thus, increasing the transcription of pro-inflammatory genes [167].

Mucus hypersecretion observed in COPD patients involves epigenetic mechanisms as DNA methylation and histone modification. COPD downregulates HDAC2, causing upregulation of the MUC5AC gene, leading to mucin production and mucus hypersecretion. Conversely, upregulation or increased HDAC2 activity can downregulate MUC5A, diminishing mucus secretion [175].

CS exposure also dysregulates in the expression of small non-coding RNA microRNA (miRNA). Izzotti et al. reported the first evidence of miRNA expression alterations caused by CS, namely downregulation of 24 miRNA involved in apoptosis, proliferation, and angiogenesis in lung [176]. The analysis of the miRNA pattern is important because miRNA senses the environmental stresses, causes phenotype changes in a cell- and tissue-specific way, being potentially used in prognostics, and contributes to the COPD pathogenesis $[177,178]$.

Advances in studying miRNA-based treatment in COPD are promising. Corticosteroids function partially through epigenetic mechanisms as miRNAs. miR-708 and miR-155 were downregulated and miR-320d and miR339-3p can be upregulated by corticoids. miR320d-increased expression diminished the activation of NF-kB signaling. miRNAs affected by corticosteroid treatment in patients with moderate to severe COPD can be considered therapeutic targets in COPD. The miR-223 plays the opposite role. miR-223 directly targets HDAC2 because miR-223 overexpression represses the activity of total HDAC and HDAC2 in pulmonary endothelial cells. COPD population has an inverse correlation between HDAC2 and miR-223 levels. The increase of HDAC2 could diminish the insensitivity GC. This miR-223 can decrease treatment efficacy in COPD patients. Several miRNAs have been modified in COPD and by classical COPD treatments. The identification of these miRNAs and description of their roles through their up- or downregulation could contribute to treatment in the future [179].

Extracellular vesicles carrying extracellular miRNA can be used to diagnose and treat COPD because miRNAs can be delivered in the specific site of action. Exosomal miRNA can be considered biomarkers for diagnosis or prognosis for COPD. A specific miRNA that is important to the better disease outcome can be delivered to the disease site through extracellular vesicles [180]. 


\section{Treatments and New Therapeutic Approaches}

Although new drug searches target different mechanisms, most drug candidates fail to reach the clinical stage of development, or fail in this phase. Therefore, management of COPD still depends on the use of bronchodilators and corticosteroids [181]. Airflow limitation occurs due to loss of elastic recoil and augmented airway resistance. Despite airflow limitation being the hallmark COPD characteristic, the primary symptom is dyspnea [182], which is related to increased resistive work. Disease progression and dynamic lung hyperinflation progressively increases residual volume after expiration, complicating the inspiratory process $[183,184]$. Bronchodilators relieve dyspnea by reducing resistive work and airway resistance $[183,185]$. Spirometry provides a more global assessment of airflow limitation, while computed tomography allows visualization of the anatomical location of the disease, enabling morphological characterization and quantitative analysis of severity contributing to phenotyping [186]. The focus on specific individual characteristics has stimulated research into treatments targeting fundamental disease mechanisms [169]. There are no specific effective pharmacological treatments for emphysema, except for those targeting $\alpha 1$ antitrypsin deficiency [187]. Modes of therapy administration include self-infusion, aerosol, and subcutaneous administration. Gene and recombinant therapies are under development [188,189], and intravenous therapy using $\alpha 1$ antitrypsin derived from human donor plasma has proven to be safe [187].

Corticosteroids (one of the main treatments used in COPD), delivered by oral administration or inhalation, are highly effective anti-inflammatory drugs for asthma. Gene transrepression caused by corticosteroids decreases NF-kB activity $[74,190]$. Nevertheless, corticoid treatment displays no anti-inflammatory effects in COPD patients. Corticosteroid resistance is primarily caused by inactivation of HDAC2, which is essential for glucocorticoid receptor (GR) repressor activity, which mediates the anti-inflammatory effect of corticosteroids $[74,167,190]$. HDAC activity represses several activated inflammatory genes, thereby inhibiting oxidative stress [191]. Reduced HDAC2 activity is observed in COPD patients [192,193]. Restoration of HDAC2 and Nrf2 levels overcomes corticosteroid resistance in COPD. Inhibition of the PI3K/Akt/p70S6K signaling pathway restores nuclear HDAC2 expression and activity. Increasing nuclear Nrf2 levels also enhances HDAC2 levels, indicating HDAC2 and Nrf2 involvement in restoring corticoid sensitivity in COPD [194].

Antioxidants and nitric oxide synthesis inhibitors can restore corticosteroid sensitivity in COPD [173]. Corticosteroids associated with bronchodilator therapy are used to prevent exacerbations [20,195]. Bronchodilators, such as long-acting $\beta 2$ agonists (LABA) and longacting muscarinic antagonists (LAMA), have beneficial effects against airflow limitation and exercise intolerance. During COPD exacerbations, LAMA is better than LABA, even when LABA is associated with an inhaled corticosteroid [20]. Unfortunately, chronic corticosteroid use can increase the risk of pneumonia in patients with severe COPD, advanced age, comorbidities, such as cardiovascular disease, skeletal muscle wasting, lung cancer, and osteoporosis, or a history of recently diagnosed pneumonia [196,197], because they are immunomodulators and immunosuppressors.

COPD exacerbations are linked to oxidative stress, promoting changes in signaling by pro-inflammatory kinases and transcription factors, steroid resistance, extracellular matrix remodeling, and mucus hypersecretion $[70,198,199]$. COPD exacerbations are linked to oxidative stress since oxidative stress impairs responses against pathogens and, consequently, contributes to exacerbations induced by viruses and bacteria, causing even more airway inflammation and more exacerbation, thus forming a repeated cycle $[200,201]$. Thus, therapies targeting oxidative imbalance are promising alternative COPD treatments [70,198,199]. Natural or synthetic antioxidants ameliorate COPD. A large number of molecules act as antioxidants, including thiol compounds (for example, GSH, N-acetyl-L-cysteine, (NAC) [202], $\mathrm{N}$-acystelyn, (NAL) [203], erdosteine [204], fudosteine [205]), polyphenolic compounds derived from the diet (e.g., curcumin [206,207], resveratrol [208], lycopene [209], alpha-lipoic acid [210], and apocynin [198,211]), Nrf2 activators (e.g., CDDO-imidazolide and sul- 
foraphane), antioxidant vitamins (e.g., vitamins C and E) [212], iNOS inhibitors [213], lipid peroxidation inhibitors/blockers, lazaroids/tirilazad [214], myeloperoxidase inhibitors, specialized pro-resolving lipid mediators [198], omega-3 fatty acids [215], and vitamin D [198]. Antioxidants act by decreasing free radical levels, and inflammatory gene expression $[71,200,216]$. Diet plays a central role in protecting against airway diseases. Carotenoids, vitamin D, vitamin E, vitamin C, curcumin, choline, and omega-3 fatty acids help protect against asthma, COPD, and lung cancer [217,218].

COPD treatment using anti-inflammatory compounds remains a challenge due to the complexity of inflammation and related comorbidities. Bronchodilators can reduce inflammation, but they can only be used for a short time, and are not effective in COPD patients [20]. Currently, no therapies effectively reverse COPD pathology. Minimizing COPD progression is an alternative therapeutic strategy. Decreasing oxidative stress and inflammation can improve quality of life and increase survival [72]. Supplementation, therapeutic administration, and/or the use of multiple antioxidants may benefit COPD patients by increasing endogenous antioxidant levels [74,219].

\section{Role of Medications of Each Drug in Patients with COPD}

Bronchodilator drugs are currently used to treat patients with COPD to improve symptoms of the disease. $\beta 2$-adrenergic receptors are present in the bronchi smooth muscles and are $G$ protein-coupled in the cell membrane; when stimulated, they increase the activity of adenyl cyclase, an enzyme that catalyzes the conversion of ATP to cyclic adenosine monophosphate (cAMP). cAMP inhibits intracellular calcium release, decreasing the influx of calcium through the membrane, relaxing smooth muscles, and dilating the airways. Adrenergic receptor agonists may be short-acting bronchodilators (SABA), such as albuterol, used for rapid relief of acute symptoms, or long-acting bronchodilators (LABA), such as formoterol, indacaterol, salmeterol, and tiotropium, used to relieve the most common and persistent symptoms, such as cough and dyspnea $[216,220]$. Muscarinic and anticholinergic antagonists are short-acting (SAMA), such as levalbuterol, or long-acting (LAMA), such as glycopyrrolate, umeclidinium, arformoterol, and revefenacin. These drugs regulate bronchomotor tonus by stimulating their bronchi muscles-specific receptors. These receptors are G protein-coupled and have five subtypes, among them M1 and M3, which are the primary drugs targets for presenting effects of improving bronchoconstriction and mucus secretion, resulting in improved lung function and dyspnea $[221,222]$.

Corticosteroids can suppress mucus production and decrease airway obstruction due to the suppression of mRNA expression of proteins encoding the MUC5AC gene [222]. Prednisolone and budesonide are used for COPD treatment in combination therapy with bronchodilators and improved symptoms in patients with a history of multiple severe exacerbations [223]. The activation of $\beta 2$-adrenergic receptors potentiates the anti-inflammatory effect of corticosteroids by increasing the glucocorticosteroid receptor translocation from the cytoplasm to the nucleus $[224,225]$. Combining corticosteroid therapy with bronchodilators or double-acting bronchodilators (muscarinic antagonists and $\beta 2$-adrenergic agonists-MABA) has proven beneficial to treat COPD patients' symptoms and exacerbation [225-227]. Viral and bacterial infections are the most frequent cause of exacerbation, which include Haemophilus influenzae (NTHi), Moraxella catarrhalis, Streptococcus pneumoniae, Pseudomonas aeruginosa, human Rhinovirus (HRV), Influenza virus, Coronavirus, and Respiratory syncytial virus (RSV) [65]. Antibiotics are being tested to treat bacterial origin exacerbation, such as aismigen, levofloxacin, and ciprofloxacin, already used in tuberculosis and sinusitis treatment. Azithromycin is being tested in viral exacerbations in a mechanism involving interferon response and decreased inflammatory mediator production. Table 1 shows updated research on new drugs for COPD treatment. The tables include drug names, administration form, drug target, registration study number, phase of development and current status, and whether the drug described has already been approved and used or not for the treatment of COPD or other disease COPD comorbidities, as exacerbation because of viral and bacterial infections is the leading cause of hospitalizations and worsening 
of symptoms. Table 2 shows the current studies treating exacerbations due to bacterial and viral infection. Table 3 shows the different methodologies used in pre-clinical studies. The methodology shows how studies of current clinical treatments for COPD were caried out. The results of these studies are shown in the tables below. We will discuss some of these next.

Table 1. Updating drug research for COPD treatment.

\begin{tabular}{|c|c|c|c|c|c|c|c|}
\hline $\begin{array}{c}\text { Drug } \\
\text { Other Names }\end{array}$ & Use & Target/Action & Identification & Phase & Status & $\begin{array}{l}\text { Approved } \\
\text { COPD } \\
\text { Treatment }\end{array}$ & $\begin{array}{c}\text { Approved } \\
\text { Treatment for } \\
\text { Another Disease }\end{array}$ \\
\hline $\begin{array}{l}\text { Canakinumab } \\
\text { ACZ885 }\end{array}$ & Antibody & IL-1 $\beta$ inhibitor & NCT00581945 & $1 / 2$ & Completed & & $\begin{array}{l}\text { Adult-onset } \\
\text { Still's disease, } \\
\text { Gouty arthritis, } \\
\text { and others }\end{array}$ \\
\hline ABX-IL8 & Antibody & IL-8 inhibitor & NCT00035828 & 2 & Completed & & \\
\hline $\begin{array}{c}\text { Infliximab } \\
\text { Remicade, TA-650 }\end{array}$ & Antibody & TNF- $\alpha$ inhibitor & NCT00056264 & 3 & Completed & & $\begin{array}{l}\text { Ankylosing } \\
\text { spondylitis, } \\
\text { Crohn's disease, } \\
\text { and others }\end{array}$ \\
\hline \multirow{2}{*}{$\begin{array}{c}\text { Mepolizumab } \\
\text { SB-240563, Bosatria, } \\
\text { Nucala }\end{array}$} & \multirow{2}{*}{ Antibody } & \multirow{2}{*}{ IL-5 inhibitor } & NCT04075331 & $2 / 3$ & Recruiting & & \multirow{2}{*}{ Asthma } \\
\hline & & & NCT01463644 & 3 & Completed & & \\
\hline $\begin{array}{l}\text { Ensifentrine } \\
\text { RPL554 }\end{array}$ & Uninformed & PDE3/PDE4 inhibitor & $\begin{array}{l}\text { NCT03443414 } \\
\text { NCT04091360 }\end{array}$ & $\begin{array}{l}2 \\
2\end{array}$ & $\begin{array}{l}\text { Completed } \\
\text { Completed }\end{array}$ & & \\
\hline $\begin{array}{l}\text { Roflumilast } \\
\text { Daliresp }\end{array}$ & Oral & PDE4 inhibitor & NCT01509677 & 3 & Completed & Yes & \\
\hline AZD2115 & \multirow[t]{2}{*}{ Inhaled } & MABA & $\begin{array}{l}\text { NCT01498081 } \\
\text { NCT02109406 }\end{array}$ & $\begin{array}{l}2 \\
2\end{array}$ & $\begin{array}{l}\text { Completed } \\
\text { Completed }\end{array}$ & & \\
\hline $\begin{array}{l}\text { MEDI8968 } \\
\text { AMG-108 }\end{array}$ & & IL-1 antagonist & NCT01448850 & 2 & Completed & & \\
\hline Benralizumab & Antibody & IL-5 inhibitor & $\begin{array}{l}\text { NCT01227278 } \\
\text { NCT04053634 }\end{array}$ & $\begin{array}{l}2 \\
3\end{array}$ & $\begin{array}{l}\text { Completed } \\
\text { Recruiting }\end{array}$ & & \multirow[t]{2}{*}{ Asthma } \\
\hline AZD1236 & & MMP-9/12 inhibitor & NCT00758706 & 2 & Completed & & \\
\hline $\begin{array}{c}\text { Glycopyrrolate } \\
\text { SUN-101, Glycopyrrolate } \\
\text { bromide, glycopyrronium } \\
\text { bromide, NVA-237, } \\
\text { AD-237 Seebri Breezhaler, } \\
\text { CHF-5259 }\end{array}$ & Inhaled & M3 receptor antagonists & $\begin{array}{l}\text { NCT00545311 } \\
\text { NCT00242333 } \\
\text { NCT00856193 } \\
\text { NCT02680197 } \\
\text { NCT02189577 } \\
\text { NCT02347761 } \\
\text { NCT01566604 } \\
\text { NCT01154127 } \\
\text { NCT01715298 } \\
\text { NCT01005901 } \\
\text { NCT02371629 }\end{array}$ & $\begin{array}{l}1 \\
2 \\
2 \\
2 \\
2 \\
3 \\
3 \\
3 \\
3 \\
3 \\
4\end{array}$ & $\begin{array}{l}\text { Completed } \\
\text { Completed } \\
\text { Completed } \\
\text { Completed } \\
\text { Completed } \\
\text { Completed } \\
\text { Completed } \\
\text { Completed } \\
\text { Completed } \\
\text { Completed } \\
\text { Completed }\end{array}$ & Yes & \\
\hline $\begin{array}{l}\text { Glycopyrrolate-formoterol } \\
\text { Bevespi Aerosphere }\end{array}$ & Inhaled & MABA & $\begin{array}{l}\text { NCT01854645 } \\
\text { NCT01854658 } \\
\text { NCT01970878 }\end{array}$ & $\begin{array}{l}3 \\
3 \\
3\end{array}$ & $\begin{array}{l}\text { Completed } \\
\text { Completed } \\
\text { Completed }\end{array}$ & Yes & \\
\hline $\begin{array}{l}\text { Glycopyrrolate- } \\
\text { indacaterol } \\
\text { Utibron Neohaler }\end{array}$ & Inhaled & MABA & $\begin{array}{l}\text { NCT01727141 } \\
\text { NCT01712516 } \\
\text { NCT01682863 } \\
\end{array}$ & $\begin{array}{l}3 \\
3 \\
3 \\
\end{array}$ & $\begin{array}{l}\text { Completed } \\
\text { Completed } \\
\text { Completed } \\
\end{array}$ & Yes & \\
\hline Simvastatin & Oral & $\begin{array}{c}\text { HMG-CoA reductase } \\
\text { inhibitors } \\
\text { Nitric oxide synthase type II } \\
\text { Inhibitors } \\
\text { IL-17 }\end{array}$ & $\begin{array}{l}\text { NCT01944176 } \\
\text { NCT02070133 }\end{array}$ & 3 & $\begin{array}{l}\text { Completed } \\
\text { Completed }\end{array}$ & & $\begin{array}{c}\text { Diabetic } \\
\text { cardiomiopathy, } \\
\text { HCL }^{1} \\
\text { hyperlipidemia, } \\
\text { and others }\end{array}$ \\
\hline Rhodiola Crenulata & Oral & $\begin{array}{l}\text { Anti-inflammation and } \\
\text { anti-oxidation }\end{array}$ & NCT02242461 & 2 & Completed & & \\
\hline $\begin{array}{l}\text { Revefenacin } \\
\text { GSK1160724, } \\
\text { TD-4208 }\end{array}$ & Inhaled & $\mathrm{mAChR}$ antagonist & $\begin{array}{l}\text { NCT00555022 } \\
\text { NCT02040792 } \\
\text { NCT02109172 } \\
\text { NCT02512510 }\end{array}$ & $\begin{array}{l}1 \\
2 \\
2 \\
3\end{array}$ & $\begin{array}{l}\text { Completed } \\
\text { Completed } \\
\text { Completed } \\
\text { Completed }\end{array}$ & Yes & \\
\hline $\begin{array}{c}\text { Sulforaphane } \\
\text { SFX-01, } \\
\text { Broccoli-sprout-extract }\end{array}$ & Oral & Nrf2 stimulator & NCT01335971 & 2 & Completed & & \\
\hline $\begin{array}{c}\text { QVA149 } \\
\text { Indacaterol maleate/ } \\
\text { glycopyrronium bromide, } \\
\text { NVA-237/QAB-149 }\end{array}$ & Inhaled & MABA & $\begin{array}{l}\text { NCT01996319 } \\
\text { NCT01120717 } \\
\end{array}$ & $\begin{array}{l}3 \\
3\end{array}$ & $\begin{array}{l}\text { Completed } \\
\text { Completed }\end{array}$ & Yes & \\
\hline Indacanterol & Inhaled & LABA & $\begin{array}{l}\text { NCT00636961 } \\
\text { NCT00792805 } \\
\text { NCT01543828 }\end{array}$ & $\begin{array}{l}2 \\
3 \\
4\end{array}$ & $\begin{array}{l}\text { Completed } \\
\text { Completed } \\
\text { Completed }\end{array}$ & Yes & \\
\hline
\end{tabular}


Table 1. Cont.

\begin{tabular}{|c|c|c|c|c|c|c|c|}
\hline $\begin{array}{l}\text { Drug } \\
\text { Other Names }\end{array}$ & Use & Target/Action & Identification & Phase & Status & $\begin{array}{l}\text { Approved } \\
\text { COPD } \\
\text { Treatment }\end{array}$ & $\begin{array}{c}\text { Approved } \\
\text { Treatment for } \\
\text { Another Disease }\end{array}$ \\
\hline CHF6523 & Uninformed & PI3K inhibitor & NCT04032535 & 1 & Recruiting & & \\
\hline AZD8683 & Inhaled & M3 receptor antagonist & NCT01205269 & 2 & Completed & & \\
\hline $\begin{array}{c}\text { Tiotropium bromide } \\
\text { Ba } 679 \text { BR, Spiriva, } \\
\text { PUR-0200 }\end{array}$ & Inhaled & $\begin{array}{l}\text { M1 and M3 receptor } \\
\text { antagonist }\end{array}$ & $\begin{array}{l}\text { NCT01921712 } \\
\text { NCT02671825 } \\
\text { NCT02172352 } \\
\text { NCT02173342 } \\
\text { NCT00292448 } \\
\text { NCT02172391 } \\
\text { NCT00143339 } \\
\text { NCT00274573 } \\
\text { NCT00274547 } \\
\text { NCT02172378 } \\
\text { NCT00274053 } \\
\text { NCT00168831 } \\
\text { NCT0406161 } \\
\text { NCT00523991 } \\
\text { NCT01072396 } \\
\text { NCT00274079 }\end{array}$ & $\begin{array}{l}1 \\
1 \\
2 \\
2 \\
2 \\
3 \\
3 \\
3 \\
3 \\
3 \\
3 \\
3 \\
4 \\
4 \\
4 \\
4\end{array}$ & $\begin{array}{l}\text { Completed } \\
\text { Completed } \\
\text { Completed } \\
\text { Completed } \\
\text { Completed } \\
\text { Completed } \\
\text { Completed } \\
\text { Completed } \\
\text { Completed } \\
\text { Completed } \\
\text { Completed } \\
\text { Completed } \\
\text { Recruiting } \\
\text { Completed } \\
\text { Completed } \\
\text { Completed }\end{array}$ & Yes & Asthma \\
\hline $\begin{array}{c}\text { Bambuterol } \\
\text { Bambec, KWD } 2183\end{array}$ & Oral & ADRB2 agonist & NCT01796730 & 4 & Completed & Yes & $\begin{array}{l}\text { Asthma and } \\
\text { bronchitis }\end{array}$ \\
\hline AZD3199 & Inhaled & ADRB2 agonist & NCT00929708 & 2 & Completed & & \\
\hline $\begin{array}{c}\text { PT003 } \\
\text { Formoterol/ } \\
\text { glycopyrrolate, } \\
\text { PT005/PT001, GFF MDI, } \\
\text { Bevespi }\end{array}$ & Inhaled & MABA & $\begin{array}{l}\text { NCT04087590 } \\
\text { NCT02347085 } \\
\text { NCT02643082 }\end{array}$ & $\begin{array}{l}2 \\
3 \\
3\end{array}$ & $\begin{array}{l}\text { Recruiting } \\
\text { Completed } \\
\text { Completed }\end{array}$ & Yes & \\
\hline $\begin{array}{c}\text { Astegolimab } \\
\text { MSTT1041A, AMG 282, } \\
\text { Anti-ST2, RO 7187807 }\end{array}$ & Antibody & IL-33 inhibitor & NCT03615040 & 2 & Completed & & \\
\hline AZD1981 & Oral & CRTH2 antagonist & NCT00690482 & 2 & Completed & & \\
\hline $\begin{array}{c}\text { Abetiterol } \\
\text { LAS100977, AZD-0548 }\end{array}$ & Inhaled & LABA & $\begin{array}{l}\text { NCT01425814 } \\
\text { NCT01425801 }\end{array}$ & $\begin{array}{l}2 \\
2 \\
\end{array}$ & $\begin{array}{l}\text { Completed } \\
\text { Completed }\end{array}$ & & \\
\hline $\begin{array}{l}\text { Formoterol fumarate } \\
\text { CHF } 1531\end{array}$ & Inhaled & LABA & NCT00215436 & 3 & Completed & Yes & Asthma \\
\hline $\begin{array}{l}\text { CHF } 6001 \\
\text { Tanimilast }\end{array}$ & Inhaled & PDE4 inhibitor & $\begin{array}{l}\text { NCT01703052 } \\
\text { NCT02386761 } \\
\text { NCT01730404 } \\
\text { NCT03004417 }\end{array}$ & $\begin{array}{l}1 \\
1 \\
2 \\
2\end{array}$ & $\begin{array}{l}\text { Completed } \\
\text { Completed } \\
\text { Completed } \\
\text { Completed }\end{array}$ & & \\
\hline DNK333 & Uninformed & NK1/NK2 antagonist & NCT01287325 & $\frac{1}{2}$ & Completed & & \\
\hline $\begin{array}{l}\text { Aclidinium Bromide } \\
\text { LAS 34273, KRP-AB1102, } \\
\text { Bretaris Genuair, Eklira } \\
\text { Genuair, Tudorza }\end{array}$ & Inhaled & M3 receptor inhibitor & $\begin{array}{l}\text { NCT03276052 } \\
\text { NCT01471171 } \\
\text { NCT00970268 } \\
\text { NCT00891462 } \\
\text { NCT00358436 } \\
\text { NCT00500318 } \\
\text { NCT01966107 }\end{array}$ & $\begin{array}{l}1 \\
3 \\
3 \\
3 \\
3 \\
3 \\
4\end{array}$ & $\begin{array}{c}\text { Not yet } \\
\text { recruiting } \\
\text { Completed } \\
\text { Completed } \\
\text { Completed } \\
\text { Completed } \\
\text { Completed } \\
\text { Completed }\end{array}$ & Yes & \\
\hline Quercetin & Oral & $\begin{array}{l}\text { Inflammation and oxidative } \\
\text { stress }\end{array}$ & $\begin{array}{l}\text { NCT01708278 } \\
\text { NCT03989271 }\end{array}$ & $\begin{array}{c}1 \\
1 / 2\end{array}$ & $\begin{array}{l}\text { Completed } \\
\text { Recruiting }\end{array}$ & & \\
\hline $\begin{array}{l}\text { Arformoterol tartrate } \\
\text { Brovana }\end{array}$ & Inhaled & LABA & $\begin{array}{l}\text { NCT00691405 } \\
\text { NCT00250679 } \\
\text { NCT00909779 } \\
\end{array}$ & $\begin{array}{l}2 \\
3 \\
3 \\
\end{array}$ & $\begin{array}{l}\text { Completed } \\
\text { Completed } \\
\text { Completed } \\
\end{array}$ & Yes & \\
\hline BIO-11006 & Inhaled & MARCKS inhibitor & NCT00648245 & 2 & Completed & & \\
\hline Bimosiamose & Inhaled & Pan-selectin antagonist & NCT01108913 & 2 & Completed & & \\
\hline QBW251 & Oral & CFTR stimulant & $\begin{array}{l}\text { NCT02449018 } \\
\text { NCT04268823 }\end{array}$ & $\begin{array}{l}2 \\
2\end{array}$ & $\begin{array}{l}\text { Completed } \\
\text { Recruiting }\end{array}$ & & \\
\hline Bufei Jianpi granule & Oral & $\begin{array}{l}\text { Elaying pulmonar function } \\
\text { decline }\end{array}$ & NCT03976700 & 3 & $\begin{array}{l}\text { Not yet } \\
\text { recruiting }\end{array}$ & & \\
\hline $\begin{array}{c}\text { Alvelestat } \\
\text { MPH966, AZD9668 }\end{array}$ & Oral & Neutrophil elastase inhibitor & $\begin{array}{l}\text { NCT01035411 } \\
\text { NCT03679598 } \\
\text { NCT00703391 } \\
\text { NCT01054170 } \\
\end{array}$ & $\begin{array}{l}1 \\
2 \\
2 \\
2\end{array}$ & $\begin{array}{l}\text { Completed } \\
\text { Recruiting } \\
\text { Completed } \\
\text { Completed }\end{array}$ & & \\
\hline $\begin{array}{l}\text { Tetomilast } \\
\text { OPC-6535 }\end{array}$ & Oral & PDE4 inhibitor & NCT00917150 & 2 & Completed & & \\
\hline Ipratropium Bromide & Inhaled & LAMA & $\begin{array}{l}\text { NCT02236182 } \\
\text { NCT00202176 }\end{array}$ & $\begin{array}{l}2 \\
4\end{array}$ & $\begin{array}{l}\text { Completed } \\
\text { Completed }\end{array}$ & Yes & \\
\hline $\begin{array}{l}\text { Setileuton } \\
\text { MK-0633 }\end{array}$ & & 5-LOX inhibitor & NCT00418613 & 2 & Completed & & \\
\hline
\end{tabular}


Table 1. Cont.

\begin{tabular}{|c|c|c|c|c|c|c|c|}
\hline $\begin{array}{c}\text { Drug } \\
\text { Other Names }\end{array}$ & Use & Target/Action & Identification & Phase & Status & $\begin{array}{l}\text { Approved } \\
\text { COPD } \\
\text { Treatment }\end{array}$ & $\begin{array}{c}\text { Approved } \\
\text { Treatment for } \\
\text { Another Disease }\end{array}$ \\
\hline Cyclosporine & Oral & $\begin{array}{l}\text { Calcineurin } \\
\text { inhibitor }\end{array}$ & NCT00974142 & $1 / 2$ & Completed & & \\
\hline $\begin{array}{c}\text { PT010 } \\
\text { Budesonide/ } \\
\text { formoterol/glycopyrrolate, } \\
\text { BGF-MDI, } \\
\text { Budesonide/PT } 003 \\
\end{array}$ & Inhaled & $\begin{array}{l}\text { ICS/LAMA/ } \\
\text { LABA }\end{array}$ & NCT03906045 & 1 & Completed & Yes & \\
\hline Lovastatin & Oral & $\begin{array}{l}\text { HMG-CoA reductase } \\
\text { inhibitor }\end{array}$ & NCT00700921 & 2 & Completed & & $\begin{array}{c}\text { HCL }^{1} \text { and } \\
\text { hyperlipidemia }\end{array}$ \\
\hline $\begin{array}{c}\text { Reldesemtiv } \\
\text { CK-107, CK-2127107 } \\
\end{array}$ & Oral & Troponin stimulant & NCT02662582 & 2 & Completed & & \\
\hline $\begin{array}{c}\text { Symbicort } \\
\text { Budesonide-formoterol }\end{array}$ & Inhaled & ICS/LABA & $\begin{array}{l}\text { NCT00206154 } \\
\text { NCT00206167 }\end{array}$ & $\begin{array}{l}3 \\
3\end{array}$ & $\begin{array}{l}\text { Completed } \\
\text { Completed }\end{array}$ & Yes & $\begin{array}{l}\text { Asthma, Crohn's } \\
\text { disease, and } \\
\text { ulcerative colitis }\end{array}$ \\
\hline Rosuvastatin & Oral & $\begin{array}{l}\text { HMG-CoA reductase } \\
\text { inhibitor }\end{array}$ & NCT00929734 & 2 & Completed & & $\begin{array}{l}\text { Atherosclerosis, } \\
\text { cardiovascular } \\
\text { disorders, HCL }{ }^{1}, \\
\text { and others }\end{array}$ \\
\hline $\begin{array}{c}\text { Dilmapimod } \\
\text { GSK 681323, SB681323 }\end{array}$ & Uninformed & p38 MAPK inhibitor & NCT00144859 & 2 & Completed & & \\
\hline Losartan & Oral & AT1 receptor antagonist & $\begin{array}{l}\text { NCT00720226 } \\
\text { NCT02696564 }\end{array}$ & $\begin{array}{l}4 \\
4\end{array}$ & $\begin{array}{c}\text { Completed } \\
\text { Active, not } \\
\text { recruiting }\end{array}$ & & $\begin{array}{c}\text { Diabetic } \\
\text { nephropathies, } \\
\text { heart failure, and } \\
\text { hypertension }\end{array}$ \\
\hline $\begin{array}{r}\text { Levalbuterol } \\
\text { Xopenex HFA }\end{array}$ & Inhaled & SAMA & NCT00665600 & 3 & Completed & Yes & Asthma \\
\hline $\begin{array}{l}\text { Albuterol } \\
\text { Salbutamol }\end{array}$ & $\begin{array}{l}\text { Spray aerosol, } \\
\text { injectable } \\
\text { or inhaled }\end{array}$ & SABA & NCT00440245 & 4 & Completed & Yes & Asthma \\
\hline $\begin{array}{l}\text { Albuterol-ipratrópio } \\
\text { Combivent Respimat }\end{array}$ & Inhaled & MABA & NCT00400153 & 3 & Completed & Yes & \\
\hline AZD2423 & Oral & CCR2 antagonist & NCT01153321 & 2 & Completed & & \\
\hline PH-797804 & Oral & p38 MAPK inhibitor & $\begin{array}{l}\text { NCT00559910 } \\
\text { NCT01321463 }\end{array}$ & $\begin{array}{l}2 \\
2\end{array}$ & $\begin{array}{l}\text { Completed } \\
\text { Completed }\end{array}$ & & \\
\hline CHF6366 & Inhaled & MABA & NCT03378648 & $1 / 2$ & Completed & & \\
\hline $\begin{array}{l}\text { Indacaterol } \\
\text { Arcapta }\end{array}$ & Inhaled & LABA & NCT00624286 & 3 & Completed & Yes & \\
\hline $\begin{array}{l}\text { MEDI2338 } \\
\text { CERC } 007\end{array}$ & Intravenous & IL-18 inhibitor & NCT01322594 & 1 & Completed & & \\
\hline AZD5069 & Oral & CXCR2 antagonist & NCT01233232 & 2 & Completed & & \\
\hline UMC119-06 & Intravenous & Cell replacements & NCT04206007 & 1 & Recruiting & & \\
\hline ION-827359 & Inhaled & $\begin{array}{c}\text { Epithelial sodium channel } \\
\text { antagonist }\end{array}$ & NCT04441788 & 2 & Recruiting & & \\
\hline Erdosteine & Oral & Glycoprotein inhibitor & NCT00338507 & 2 & Completed & Yes & Bronchitis \\
\hline $\begin{array}{l}\text { RV1162 } \\
\text { PUR } 1800\end{array}$ & Inhaled & $\begin{array}{c}\text { Narrow-spectrum kinase } \\
\text { inhibitor }\end{array}$ & NCT01970618 & 1 & Completed & & \\
\hline $\begin{array}{c}\text { JNJ } 49095397 \\
\text { RV568 }\end{array}$ & Inhaled & PTS inhibitors & NCT01867762 & 2 & Completed & & \\
\hline Selenium & Oral & GPx-1 levels & NCT00186706 & 4 & Completed & & \\
\hline $\begin{array}{c}\text { Epeleuton } \\
\text { DS102, 15-HEPE, AF-102 }\end{array}$ & Oral & 5-LOX inhibitor & NCT03414541 & 2 & Completed & & \\
\hline AZD8871 & Inhaled & MABA & $\begin{array}{l}\text { NCT02814656 } \\
\text { NCT02971293 }\end{array}$ & $\begin{array}{l}1 \\
2 \\
\end{array}$ & $\begin{array}{l}\text { Completed } \\
\text { Completed }\end{array}$ & & \\
\hline $\begin{array}{c}\text { CHF } 5993 \\
\text { Beclometasone/formoterol/ } \\
\text { glycopyrrolate, } \\
\text { BDP/FF/GB }\end{array}$ & Inhaled & $\begin{array}{l}\text { ICS/LABA/ } \\
\text { LAMA }\end{array}$ & NCT02743013 & 1 & Completed & Yes & Asthma \\
\hline $\begin{array}{c}\text { Vilanterol } \\
\text { GW642444 }\end{array}$ & Inhaled & LABA & $\begin{array}{l}\text { NCT00372112 } \\
\text { NCT00606684 }\end{array}$ & $\begin{array}{l}2 \\
2\end{array}$ & $\begin{array}{l}\text { Completed } \\
\text { Completed }\end{array}$ & & \\
\hline GSK256066 & Inhaled & $\begin{array}{l}\text { Type } 4 \text { cyclic nucleotide } \\
\text { PDE inhibitors }\end{array}$ & NCT00549679 & 2 & Completed & & \\
\hline PF00610355 & Inhaled & ADRB2 agonist & NCT00808288 & 2 & Completed & & \\
\hline $\begin{array}{l}\text { Umeclidinium } \\
\text { GSK573719, Incruse } \\
\text { Ellipta }\end{array}$ & Inhaled & LAMA & $\begin{array}{l}\text { NCT01110018 } \\
\text { NCT00950807 } \\
\text { NCT00732472 } \\
\text { NCT01030965 } \\
\text { NCT01387230 } \\
\text { NCT02184611 }\end{array}$ & $\begin{array}{l}1 \\
2 \\
2 \\
2 \\
3 \\
3\end{array}$ & $\begin{array}{l}\text { Completed } \\
\text { Completed } \\
\text { Completed } \\
\text { Completed } \\
\text { Completed } \\
\text { Completed }\end{array}$ & Yes & \\
\hline
\end{tabular}


Table 1. Cont.

\begin{tabular}{|c|c|c|c|c|c|c|c|}
\hline $\begin{array}{c}\text { Drug } \\
\text { Other Names }\end{array}$ & Use & Target/Action & Identification & Phase & Status & $\begin{array}{l}\text { Approved } \\
\text { COPD } \\
\text { Treatment }\end{array}$ & $\begin{array}{c}\text { Approved } \\
\text { Treatment for } \\
\text { Another Disease }\end{array}$ \\
\hline $\begin{array}{l}\text { Umeclidinium-vilanterol } \\
\text { Anoro Elipta }\end{array}$ & Inhaled & MABA & NCT01899742 & 3 & Completed & Yes & \\
\hline $\begin{array}{l}\text { Darotropium bromide } \\
\text { GSK233705 }\end{array}$ & Inhaled & $\mathrm{mAChR}$ antagonist & $\begin{array}{l}\text { NCT00676052 } \\
\text { NCT00376714 } \\
\text { NCT00453479 } \\
\end{array}$ & $\begin{array}{l}2 \\
2 \\
2\end{array}$ & $\begin{array}{l}\text { Completed } \\
\text { Completed } \\
\text { Completed }\end{array}$ & & \\
\hline $\begin{array}{l}\text { Tiotropium-Olodaterol } \\
\text { Stiolto Respimat }\end{array}$ & Inhaled & MABA & $\begin{array}{l}\text { NCT01431274 } \\
\text { NCT01431287 }\end{array}$ & $\begin{array}{l}3 \\
3 \\
\end{array}$ & $\begin{array}{l}\text { Completed } \\
\text { Completed }\end{array}$ & Yes & \\
\hline AZD8871 & Inhaled & MABA & NCT03159442 & 1 & Completed & & \\
\hline $\begin{array}{c}\text { Oglemilast } \\
\text { GRC 3886, GRC-3836 }\end{array}$ & Oral & PD4 inhibitor & NCT00671073 & 2 & Completed & & \\
\hline $\begin{array}{c}\text { Danirixin } \\
\text { GSK-1325756 }\end{array}$ & Oral & CXCR2 antagonist & $\begin{array}{l}\text { NCT01209052 } \\
\text { NCT03034967 } \\
\text { NCT02130193 }\end{array}$ & $\begin{array}{l}1 \\
2 \\
2\end{array}$ & $\begin{array}{l}\text { Completed } \\
\text { Completed } \\
\text { Completed }\end{array}$ & & \\
\hline $\begin{array}{c}\text { Fluticasone Propionate/ } \\
\text { salmeterol } \\
\text { Advair HFA }\end{array}$ & Inhaled & $\begin{array}{c}\text { ICS/LABA } \\
\text { Arachidonic } \\
\text { acid inhibitors } \\
\text { Lipocortin synthesis agonists }\end{array}$ & NCT00633217 & 4 & Completed & Yes & Asthma \\
\hline $\begin{array}{l}\text { Batefenterol } \\
\text { GSK961081 }\end{array}$ & Inhaled & MABA & $\begin{array}{l}\text { NCT00887406 } \\
\text { NCT02663089 } \\
\text { NCT00478738 } \\
\text { NCT02570165 }\end{array}$ & $\begin{array}{l}1 \\
1 \\
2 \\
2\end{array}$ & $\begin{array}{l}\text { Completed } \\
\text { Completed } \\
\text { Completed } \\
\text { Completed }\end{array}$ & & \\
\hline Remestemcel-L RYONCIL & Intravenous & Stem cell therapies & NCT00683722 & 2 & Completed & & $\begin{array}{l}\text { Graft-versus- } \\
\text { host } \\
\text { disease }\end{array}$ \\
\hline Budesonida Pulmicort & Inhaled & ICS & NCT00232674 & 4 & Completed & Yes & Asthma \\
\hline $\mathrm{N}$-acetylcysteine & Oral & Antioxidant & NCT02579772 & 4 & Completed & Yes & $\begin{array}{l}\text { Bronchiectasis, } \\
\text { cystic fibrosis, } \\
\text { dry eyes, and } \\
\text { poisoning }\end{array}$ \\
\hline MK-0873 & Oral & PDE4 inhibitor & NCT00132730 & 2 & Terminated & & \\
\hline BI 1026706 & Oral & $\begin{array}{c}\text { Bradykinin B1 receptor } \\
\text { antagonist }\end{array}$ & NCT02642614 & 1 & Completed & & \\
\hline BIBW 2948 & Inhaled & EGFR inhibitor & NCT00423137 & 2 & Completed & & \\
\hline $\begin{array}{c}\text { Cilomilast } \\
\text { SB 207499, AL-38583 }\end{array}$ & Oral & PDE4 inhibitor & NCT00103922 & 3 & Completed & & \\
\hline $\begin{array}{l}\text { Olodaterol } \\
\text { BI 1744 CL, Striverdi } \\
\text { Respimat }\end{array}$ & Inhaled & LABA & $\begin{array}{l}\text { NCT00824382 } \\
\text { NCT00452400 } \\
\text { NCT01809262 } \\
\text { NCT00793624 }\end{array}$ & $\begin{array}{l}2 \\
2 \\
2 \\
3\end{array}$ & $\begin{array}{l}\text { Completed } \\
\text { Completed } \\
\text { Completed } \\
\text { Completed }\end{array}$ & Yes & \\
\hline PH-797804 & Oral & p38 inhibitor & NCT01543919 & 2 & Completed & & \\
\hline CCI15106 & Inhaled & Undefined mechanism & NCT03235726 & 1 & Completed & & \\
\hline $\begin{array}{c}\text { Losmapimod } \\
\text { GW856553X, FTX-1821 }\end{array}$ & Oral & p38 $\alpha / \beta$ MAPK inhibitor & NCT01218126 & 2 & Completed & & \\
\hline BI 113608 & Oral & Undefined mechanism & NCT01958008 & 1 & Completed & & \\
\hline TRN-157 & Inhaled & M3 receptor antagonists & NCT02133339 & 1 & Completed & & \\
\hline PF03635659 & Inhaled & Undefined mechanism & NCT00864786 & 1 & Completed & & \\
\hline CNTO 6785 & Intravenous & IL17A protein inhibitor & NCT01966549 & 2 & Completed & & \\
\hline $\begin{array}{l}\text { Sildenafil } \\
\text { Viagra }\end{array}$ & Oral & PDE5 inhibitor & NCT00104637 & 2 & Completed & & $\begin{array}{c}\text { Erectile } \\
\text { dysfunction and } \\
\text { pulmonary } \\
\text { arterial } \\
\text { hypertension }\end{array}$ \\
\hline $\begin{array}{c}\text { AZD7594 } \\
\text { AZ13189620 }\end{array}$ & Inhaled & $\begin{array}{c}\text { Glucocorticoid receptor } \\
\text { modulators }\end{array}$ & NCT02645253 & 1 & Completed & & \\
\hline $\begin{array}{l}\text { Tofimilast } \\
\text { CP } 325366\end{array}$ & Inhaled & PDE4 inhibitor & NCT00219622 & 2 & Completed & & \\
\hline $\begin{array}{c}\text { Fluticasone- } \\
\text { furoate/vilanterol }\end{array}$ & Inhaled & LABA/ICS & NCT01691885 & 3 & Completed & Yes & Asthma \\
\hline Retinoic Acid & & RAR agonists & NCT00000621 & 2 & Completed & & $\begin{array}{l}\text { Acne, acute } \\
\text { promyelocytic } \\
\text { leukaemia, } \\
\text { photodamage, } \\
\text { and warts }\end{array}$ \\
\hline Lebrikizumab & Subcutaneous & IL-13 inhibitor & NCT02546700 & 2 & Completed & & \\
\hline $\begin{array}{c}\text { Fluticasone- } \\
\text { umeclidinium } \\
\text { Trelegy Ellipta }\end{array}$ & Inhaled & MABA & $\begin{array}{l}\text { NCT02345161 } \\
\text { NCT02729051 }\end{array}$ & $\begin{array}{l}3 \\
3\end{array}$ & $\begin{array}{l}\text { Completed } \\
\text { Completed }\end{array}$ & Yes & Asthma \\
\hline
\end{tabular}


Table 2. Update of drug investigation for the treatment of COPD exacerbation caused by viral and bacterial infection and directed to the treatment of acute exacerbations.

\begin{tabular}{|c|c|c|c|c|c|c|c|}
\hline $\begin{array}{c}\text { Drug } \\
\text { Other Names }\end{array}$ & Use & Target/Action & Identification & Phase & Status & $\begin{array}{l}\text { Approved } \\
\text { COPD } \\
\text { Treatment }\end{array}$ & $\begin{array}{l}\text { Approved Treatment } \\
\text { for Another Disease }\end{array}$ \\
\hline Ciprofloxacin & Oral & $\begin{array}{c}\text { DNA gyrase } \\
\text { Inhibitor } \\
\text { DNA topoisomerase } \\
\text { inhibitor }\end{array}$ & NCT02300220 & 3 & Completed & & $\begin{array}{c}\text { Acute sinusitis, } \\
\text { gonorrhoea, Intestinal } \\
\text { infections, respiratory } \\
\text { tract infections, and } \\
\text { others }\end{array}$ \\
\hline $\begin{array}{l}\text { Tezepelumab } \\
\text { MEDI-9929 }\end{array}$ & Subcutaneous & $\begin{array}{l}\text { Hymic stromal } \\
\text { lymphopoietin } \\
\text { inhibitor }\end{array}$ & NCT04039113 & 2 & Recruiting & & \\
\hline $\begin{array}{c}\text { Ismigen } \\
\text { Antibacterial } \\
\text { vaccine } \\
\text { sublingual, } \\
\text { Provax, Pulmigen, } \\
\text { Respibron, } \\
\text { Bactovax, } \\
\text { Bromunyl. }\end{array}$ & Sublingual & Immunostimulants & NCT02417649 & 4 & Completed & Yes & $\begin{array}{l}\text { Respiratory tract } \\
\text { infections }\end{array}$ \\
\hline Doxycycline & Oral & $\begin{array}{l}\text { Protein } 30 \text { ribosomal } \\
\text { subunit inhibitors }\end{array}$ & NCT02305940 & 3 & Completed & & \\
\hline $\begin{array}{l}\text { Levofloxacin } \\
\text { MP-376, Quinsair, } \\
\text { Aeroquin }\end{array}$ & Inhaled & $\begin{array}{l}\text { DNA gyrase inhibitor } \\
\text { DNA topoisomerase } \\
\text { type IV and type II } \\
\text { inhibitor }\end{array}$ & NCT00739648 & 2 & Completed & & $\begin{array}{l}\text { Bacterial infections, } \\
\text { pneumonia, Sinusitis, } \\
\text { tuberculosis, and } \\
\text { others }\end{array}$ \\
\hline Roflumilast & Oral & PDE4 inhibitor & $\begin{array}{l}\text { NCT00076089 } \\
\text { NCT00430729 }\end{array}$ & $\begin{array}{l}3 \\
3 \\
\end{array}$ & Completed & Yes & \\
\hline Benralizumab & Subcutaneous & Anti-IL5R $\alpha$ antibody & $\begin{array}{l}\text { NCT04098718 } \\
\text { NCT04053634 } \\
\text { NCT02155660 }\end{array}$ & $\begin{array}{l}2 \\
3 \\
3\end{array}$ & $\begin{array}{l}\text { Not yet } \\
\text { recruiting } \\
\text { Recruiting } \\
\text { Completed }\end{array}$ & & Asthma \\
\hline $\begin{array}{c}\text { Aclidinium } \\
\text { Bromide } \\
\text { LAS 34273, } \\
\text { KRP-AB1102, } \\
\text { Bretaris Genuair, } \\
\text { Eklira Genuair, } \\
\text { Tudorza } \\
\end{array}$ & Inhaled & M3 receptor inhibitor & NCT01966107 & 4 & Completed & Yes & \\
\hline Metformin & Oral & $\begin{array}{l}\text { AMPK stimulants } \\
\text { Gluconeogenesis } \\
\text { inhibitors }\end{array}$ & NCT01247870 & 4 & Completed & & $\begin{array}{l}\text { Type } 2 \text { diabetes } \\
\text { mellitus }\end{array}$ \\
\hline Enoximone & Intravenous & PDE3 inhibitor & NCT04420455 & 4 & $\begin{array}{c}\text { Not yet } \\
\text { recruiting }\end{array}$ & & Heart failure \\
\hline QBW251 & Oral & CFTR stimulant & NCT04268823 & 2 & Recruiting & & \\
\hline $\begin{array}{c}\text { Losmapimod } \\
\text { GW856553X, } \\
\text { FTX-1821 }\end{array}$ & Oral & $\begin{array}{l}\mathrm{p} 38 \alpha / \beta \text { MAPK } \\
\text { inhibitor }\end{array}$ & NCT02299375 & 2 & Completed & & \\
\hline $\begin{array}{l}\text { Nemiralisib } \\
\text { GSK2269557 }\end{array}$ & Inhaled & PI3K $\delta$ inhibitor & NCT02294734 & 2 & Completed & & \\
\hline $\begin{array}{l}\text { Acumapimod } \\
\text { BCT197 }\end{array}$ & Oral & P38 inhibitor & NCT02700919 & 2 & Completed & & \\
\hline $\begin{array}{c}\text { Mepolizumab } \\
\text { SB-240563, } \\
\text { Bosatria, Nucala }\end{array}$ & Subcutaneous & IL-5 inhibitor & NCT04133909 & 3 & Recruiting & & Asthma \\
\hline Azithromycin & Oral & $\begin{array}{l}\text { Protein } 50 \text { ribosomal } \\
\text { subunit inhibitors }\end{array}$ & NCT04319705 & & Recruiting & & $\begin{array}{l}\text { Acute exacerbations of } \\
\text { chronic bronchitis, } \\
\text { acute sinusitis, } \\
\text { pneumonia, } \\
\text { pharyngitis, and } \\
\text { respiratory tract } \\
\text { infections } \\
\end{array}$ \\
\hline Arbidol & Oral & $\begin{array}{c}\text { DNA and RNA } \\
\text { synthesis inhibiting }\end{array}$ & NCT03851991 & & Recruiting & & \\
\hline $\begin{array}{c}\text { Anti-ST2 } \\
\text { MSTT1041A, } \\
\text { AMG 282 }\end{array}$ & Subcutaneous & IL33 inhibitors & NCT03615040 & & $\begin{array}{l}\text { Not yet } \\
\text { recruiting }\end{array}$ & & \\
\hline
\end{tabular}


Table 3. Pre-clinical research methods in vivo used in new drug discovery and development.

\begin{tabular}{|c|c|c|c|c|}
\hline Study & Treatment & Model Species & $\begin{array}{l}\text { Experimental } \\
\text { Intervention }\end{array}$ & Results \\
\hline Horio et al., 2017 & $\begin{array}{l}\text { Galectina (Gal) }-9 \\
\text { administered } \\
\text { subcutaneously once } \\
\text { daily from } 1 \text { day } \\
\text { before PPE } \\
\text { instillation to day } 5\end{array}$ & $\begin{array}{l}\text { Female C57BL / } 6 \text { mice } \\
\quad(8-10 \text { weeks old })\end{array}$ & $\begin{array}{c}\text { Lungs were } \\
\text { intratracheally } \\
\text { instilled } \\
\text { with two units of PPE } \\
\text { diluted in } 50 \mu \mathrm{L} \text { of } \\
\text { saline via } 24 \text {-gauge } \\
\text { catheter on day } 0\end{array}$ & $\begin{array}{c}\text { Infiltration of } \\
\text { neutrophils was } \\
\text { inhibited and MMP } \\
\text { levels decreased }\end{array}$ \\
\hline Melo et al, 2018 & $\begin{array}{l}\text { Atorvastatin, } 1,5 \text {, and } \\
20 \text { mg, treated from } \\
\text { day } 33 \text { until day } 64 \\
\text { via inhalation for } 10 \\
\text { min once a day }\end{array}$ & $\begin{array}{l}\text { Male C57BL/6 mice } \\
\text { (8 weeks old/18-22 g) }\end{array}$ & $\begin{array}{c}\text { Administered } \\
\text { intranasally } 4 \times 0.6 \mathrm{U} \\
\text { of porcine pancreatic } \\
\text { elastase (PPE) every } \\
\text { other day (days } 1,3,5 \\
\text { and } 7 \text { ). }\end{array}$ & $\begin{array}{l}\text { Induced lung tissue } \\
\text { repair in mice with } \\
\text { emphysema }\end{array}$ \\
\hline $\begin{array}{l}\text { Pinho-Ribeiro } \\
\text { et al., } 2017\end{array}$ & $\begin{array}{c}\text { Atorvastatin and } \\
\text { simvastatin } \\
\text { administered via } \\
\text { inhalation for } 15 \mathrm{~min} \\
\text { (1 mg/mL, once/day) }\end{array}$ & $\begin{array}{l}\text { Male C57BL/ } 6 \text { mice } \\
\text { (8-10 weeks old) }\end{array}$ & $\begin{array}{l}\text { Mice exposed to } \\
12 \text { cigarettes a day for } \\
60 \text { days, then treated } \\
\text { for another } 60 \text { days }\end{array}$ & $\begin{array}{l}\text { Improved lung repair } \\
\text { after cigarette } \\
\text { smoke-induced } \\
\text { emphysema, } \\
\text { accompanied by a } \\
\text { reduction in oxidative } \\
\text { stress markers. }\end{array}$ \\
\hline Sun et al., 2017 & $\begin{array}{c}\text { Simvastatin } \\
\text { administered } \\
\text { intra-gastrically at a } \\
\text { dose of } 5 \mathrm{mg} / \mathrm{kg} / \text { day } \\
\text { followed by CS }\end{array}$ & $\begin{array}{c}\text { Male Sprague Dawley } \\
\text { (SD) rats (6 weeks } \\
\text { old } / 110-20 \mathrm{~g})\end{array}$ & $\begin{array}{c}\text { Animals were } \\
\text { passively exposed } \\
\text { (whole body) to } \\
\text { smoke from } \\
20 \text { cigarettes in a box } \\
\text { for } 1 \mathrm{~h} \text {, twice a day, } \\
5 \text { days a week, for } \\
16 \text { weeks }\end{array}$ & $\begin{array}{l}\text { Partial blockage of } \\
\text { airway inflammation, } \\
\text { and MMP production }\end{array}$ \\
\hline Susuki et al., 2009 & $\begin{array}{l}\text { Curcumin (100 } \\
\mathrm{mg} / \mathrm{kg}) \\
\text { administrated daily } \\
\text { by oral gavage } \\
\text { throughout a } 21 \text {-day } \\
\text { period }\end{array}$ & $\begin{array}{l}\text { Male C57BL/6J mice } \\
\quad \text { (9 weeks old) }\end{array}$ & $\begin{array}{c}\text { Administered } \\
\text { intratracheal porcine } \\
\text { pancreatic elastase } \\
\text { (PPE), or exposed to } \\
\text { CS (60 min/day for } \\
10 \text { consecutive days, } \\
\text { or } 5 \text { days / week for } \\
12 \text { weeks) }\end{array}$ & $\begin{array}{c}\text { Inhibited } \\
\text { PPE-induced increase } \\
\text { in neutrophils, } \\
\text { inhibited increase in } \\
\text { neutrophils and } \\
\text { macrophages in BAL, } \\
\text { and attenuated } \\
\text { increase in air space } \\
\text { induced by CS }\end{array}$ \\
\hline $\begin{array}{l}\text { Kennedy-Feitosa } \\
\text { et al., } 2018\end{array}$ & $\begin{array}{l}\text { Inhalation of } 1 \\
\mathrm{mg} / \mathrm{mL} \text { or } 10 \mathrm{mg} / \mathrm{mL} \\
\text { eucalyptol for } 15 \mathrm{~min} \\
\text { per day }\end{array}$ & $\begin{array}{l}\text { Male C57BL/6 mice } \\
\text { (8 weeks old/18-25 g) }\end{array}$ & $\begin{array}{l}\text { Mice exposed to } \\
12 \text { cigarettes a day for } \\
60 \text { days, then treated } \\
\text { for another } 60 \text { days } \\
\text { without exposure } \\
\text { to smoke }\end{array}$ & $\begin{array}{l}\text { Lung repair, reduced } \\
\text { inflammatory } \\
\text { cytokines and NE } \\
\text { levels, and increased } \\
\text { elastin and TIMP-1 } \\
\text { levels. }\end{array}$ \\
\hline Boo et al., 2020 & $\begin{array}{l}\mathrm{LJ}-2698(50 \mu \mathrm{g} / \mathrm{kg}) \\
\text { administrated by oral } \\
\text { gavage six times per } \\
\text { week for } 5 \text { weeks. }\end{array}$ & $\begin{array}{c}\text { FVB mice } \\
(8 \text { weeks old })\end{array}$ & $\begin{array}{l}\text { One week after drug } \\
\text { treatment, } 0.25 \text { units } \\
\text { of PPE was } \\
\text { intratracheally } \\
\text { instilled into the } \\
\text { lungs of the mice }\end{array}$ & $\begin{array}{c}\text { Induction of } \\
\text { anti-inflammatory } \\
\text { cytokine production } \\
\text { and recruitment of } \\
\text { M2 macrophages }\end{array}$ \\
\hline
\end{tabular}

Atorvastatin and simvastatin decrease cytokine and leukocyte levels, reduce oxidative stress markers, and improve lung repair [228,229]. Statins can modulate the lung's extracellular matrix composition because statins may directly regulate MMPs or their biological inhibitors, the TIMPS (inhibitors of matrix metalloproteinases), improving lung function through structural changes [230].

Curcumin obtained from turmeric (Curcumina longa) is a polyphenol with antioxidant and anti-inflammatory properties $[206,207]$ that modulates glutathione levels and inhibits IL-8 release in lung cells [198]. Studies have shown that curcumin treatment inhibits 
the increases in neutrophils and macrophages in the BALF of mice exposed to CS and attenuates increases in air space in mice exposed to CS or porcine pancreatic elastase [207].

Eucalyptol (1,8-cineole) is a promising adjunct or anti-inflammatory therapy for COPD and exacerbations [231-233] that promotes bacterial elimination in lungs exposed to tobacco, reducing damage to ciliated cells and suppressing expression of MUC5AC in the lungs [234]. Eucalyptol promoted pulmonary repair and decreased levels of MPO, TNF- $\alpha$, IL-1 $\beta$, IL-6, KC, TGF- $\beta 1$, and neutrophil elastase [235].

LJ-2698, an adenosine A3 receptor antagonist, significantly attenuated increases in air space, improved lung function, inhibited matrix metalloproteinase activity and lung cell apoptosis, induced increases in anti-inflammatory cytokines produced by macrophages, and significantly increased the number of M2 macrophages [236]. LJ-529, a partial peroxisome proliferator-activated gamma receptor (PPAR $\gamma$ ) agonist, showed similar results, and induced expression of PPAR $\gamma$ target genes, which play a role in regulating inflammation [237].

Therapy with mesenchymal stromal cells (MSCs) is a thoughtful approach to treating pulmonary diseases, including COPD, mainly based on the immunosuppressive role of MSCs. MSCs are promising adjuvants, used in combination with other treatments, that can improve pulmonary function and decrease inflammation through their anti-inflammatory, antioxidant, microbicidal, and angiogenic action [238,239].

Thioredoxin ( $\operatorname{Tr} x)$ is an essential regulator of the body's redox balance, which can benefit COPD patients through varied mechanisms of action, either as a primary treatment or as a coadjuvant with other treatments [240,241]. Trx also improves resistance to corticosteroids [240], inhibits elastase-induced emphysema [242], decreases neutrophilic inflation [243], and blocks the production of inflammatory cytokines [241]. Further clinical studies are required to verify its effectiveness in COPD treatment [240].

New treatment research focuses on LABA [244] and LAMA [245], such as vilanterol and umeclidinium, including inhibitors of inflammatory mediators, such as canakinumab [246], infliximab [247], and mepolizumab [248]. Phosphodiesterase (PDE) inhibitors (roflumilast and the M3 receptor antagonist glycopyrrolate) [249] exert anti-inflammatory and bronchodilator effects by inhibiting an enzyme involved in the degradation of second messengers [250]. Nevertheless, few clinical trials are currently assessing decreases in oxidative stress, which is a significant factor in COPD and its comorbidities.

Figure 3 shows the main mechanisms of action of drugs under development for COPD treatment. 


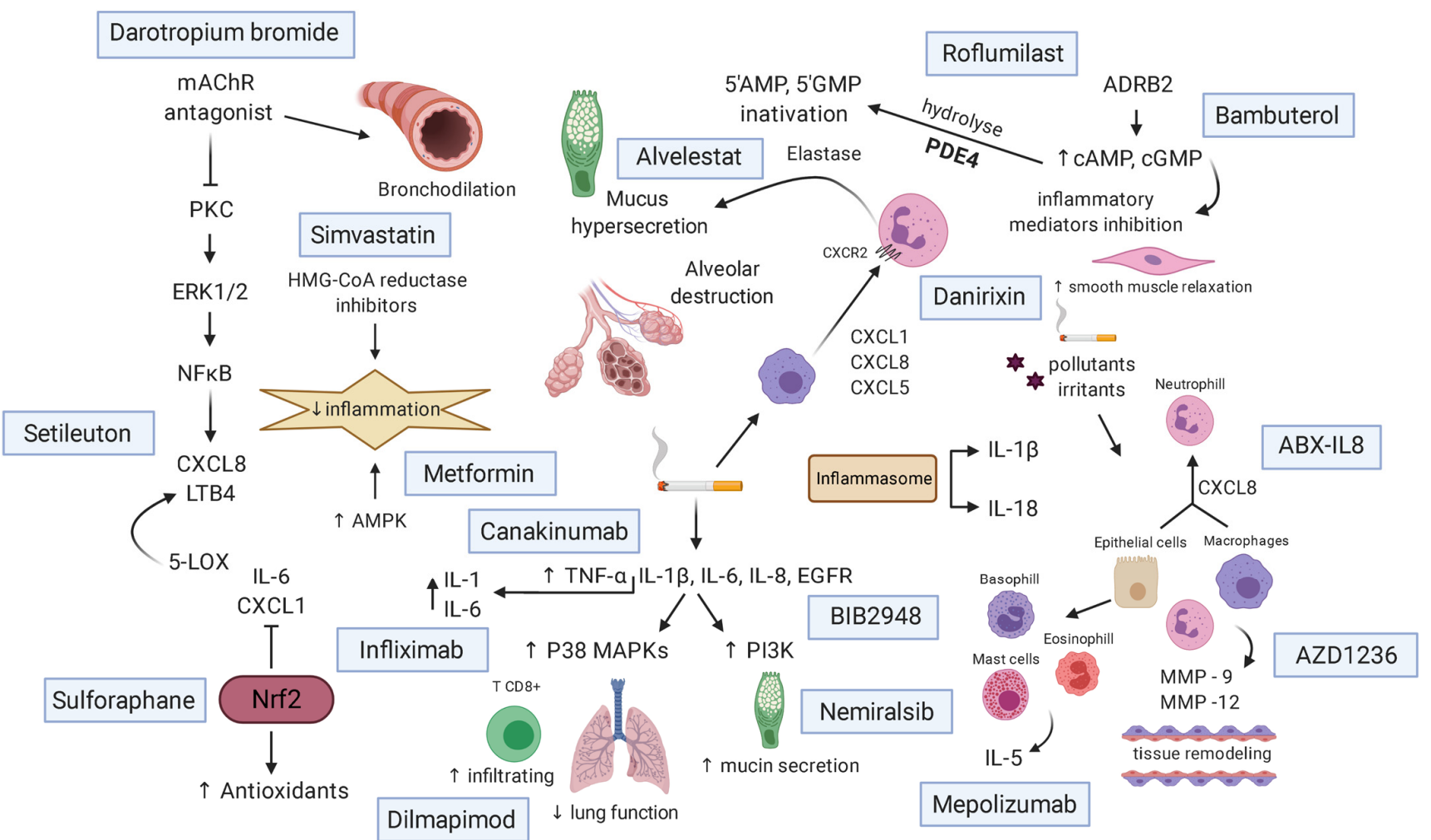

Figure 3. Mechanism of action of drugs for the treatment of COPD. Pollutants and CS initiate an inflammatory response by attracting inflammatory cells and releasing inflammatory mediators. mAChR antagonists act as bronchodilators, promoting the release of CXCL8 and LTB4. AMPK and HMG-CoA reductase stimulants decrease inflammation. Inhibitors of inflammatory mediators, such as CXCL1, CXCL8, and CXCL5, act by decreasing chemoattraction of neutrophils and macrophages to the lung (underlying inflammation). Nrf2 stimulants increase the transcription of antioxidant genes, and block the release of pro-inflammatory mediators. Interleukin, EGFR, and TNF- $\alpha$ inhibitors antagonize the activation of MAPKs and PI3K, and attenuate the release of pro-inflammatory mediators, such as IL-6 and IL-1. ADRB2 agonists inhibit the release of inflammatory mediators, cause smooth muscle relaxation, and increase cAMP and cGMP. PDE4 inhibitors prevent cAMP degradation, increasing intracellular cAMP levels, leading to smooth muscle relaxation, and enhancing the bronchodilator effects of $\beta$-agonists. CS, cigarette smoke; mAChR, Muscarinic ACh receptors AMP, adenosine monophosphate, AMPK, AMP-activated protein kinase; ADRB2, beta-2-adrenergic receptor; CXCL, chemokine; IL, interleukin; ERK, extracellular signal-regulated kinases; GMP, guanosine monophosphate; HMG-CoA, 3-hydroxymethylglutaryl CoA reductase; LOX, lipoxygenase; LTB4, leukotriene B4; MMPs, matrix metalloproteinases; ADRB2, adrenoceptor Beta 2; NFkB, factor nuclear kappa B; Nrf2, nuclear factor erythroid 2-related factor 2; PDE4, phosphodiesterase 4, PI3K, phosphoinositide 3-kinases; PKC, protein kinase C; TNF- $\alpha$, tumor necrosis factor alpha. Created with BioRender.com.

\section{COPD and COVID-19}

SARS-CoV-2 has affected more than 150 million people worldwide, and has caused more than 3 million deaths [251]. Patients with pulmonary comorbidities, such as COPD, belong to the high-risk group [252,253]. High-risk group patients are more likely to develop COVID-19 with worse progression and prognosis $[253,254]$. They present a four times greater risk of developing the severe form of the disease [254], and smokers have a higher risk of severe complications and a higher mortality rate [253]

SARS-CoV-2 uses the ACE-2 receptor (angiotensin-converting enzyme 2) to enter cells $[255,256]$. Increased airway expression of the ACE-2 receptor in COPD patients and smokers correlates with their increased risk of developing COVID-19 [252,257]. COPD patients also display changes in their renin-angiotensin-aldosterone system (RAAS), which positively regulates ACE and angiotensin II expression, potentially aggravating SARSCoV-2 infection [258]. Additionally, the remodeling and tissue repair caused by COPD alters ACE2 expression in epithelial cells [259]. SARS-CoV-2 has a spike protein (S) in its 
envelope that is activated for ACE-2 binding by serine protease TMPRSS2 (transmembrane protease, serine 2)-mediated cleavage. This protease is essential for viral infectivity and pathogenesis. The action of TMPRSS2 on the envelope protein facilitates viral entry into cells by facilitating the association with the ACE-2 receptor [260].

There are no definitive data on how COPD patient health should be managed during the current COVID-19 pandemic. Nevertheless, patients should be encouraged to continue standard therapy with inhaled corticosteroids and bronchodilators [261]. In COPD patients that develop COVID-19, the use of corticosteroids is controversial. In addition to uncertainty about their effectiveness, some studies claim that corticosteroids are contraindicated [262]. However, dexamethasone has shown a decrease in mortality in patients with COVID-19 [206], which seems to suggest their continued use for treatment of patients with pre-existing COPD who develop COVID-19.

\section{Prevention}

Quitting smoking is the best way to prevent COPD progression [182] and pathologies related to COPD, such as lung infections, lung cancer, and cardiovascular disease [20]. COPD patients report low self-esteem, low motivation to smoking cessation, and depression. Interventions that help the patient to smoking cessation, such as treatment with varenicline or bupropion (drugs that act on nicotine dependence) are fascinating [20]. Secondary prevention includes increasing physical activity in daily life, effectively preventing morbidity and mortality in COPD patients [20]. Increasing physical activity by at least 600 steps per day is associated with decreased hospitalization and COPD patient admission [263]. Secondary prevention also includes a healthy and nutritious diet, such as the Mediterranean diet, which has protective effects against respiratory diseases [264], possibly because the Mediterranean diet incorporates a balanced lipid composition with low inflammatory potential [265].

Vaccination prevents diseases in the overall population at any age. In COPD patients, vaccine in conjunction with smoking cessation, increased physical activity, and a healthy diet can improve quality of life and prevent onset of comorbidities. Influenza virus infections cause increased morbidity and mortality in COPD patients. Evidence shows decreased risk of exacerbations in patients who received influenza vaccination as a means of prevention [266]. The pneumococcal vaccine helps to keep the disease stable if administered early upon development of COPD [267].

\section{Methodology}

An initial literature research was performed by searching in the database Clinical Trials with the keyword COPD. All comparative or complementary articles as well as those with closed, retired, or unknown recruitment status were excluded. Articles selected for inclusion in this work were randomized and masked and were described in two tables, one for those intended for COPD treatment and one for those intended for COPD viral and bacterial exacerbation treatment or those aimed at improving acute exacerbations. Figure 4 shows how studies of current clinical treatments for COPD were carried out. The results of these studies are shown in the tables below. 


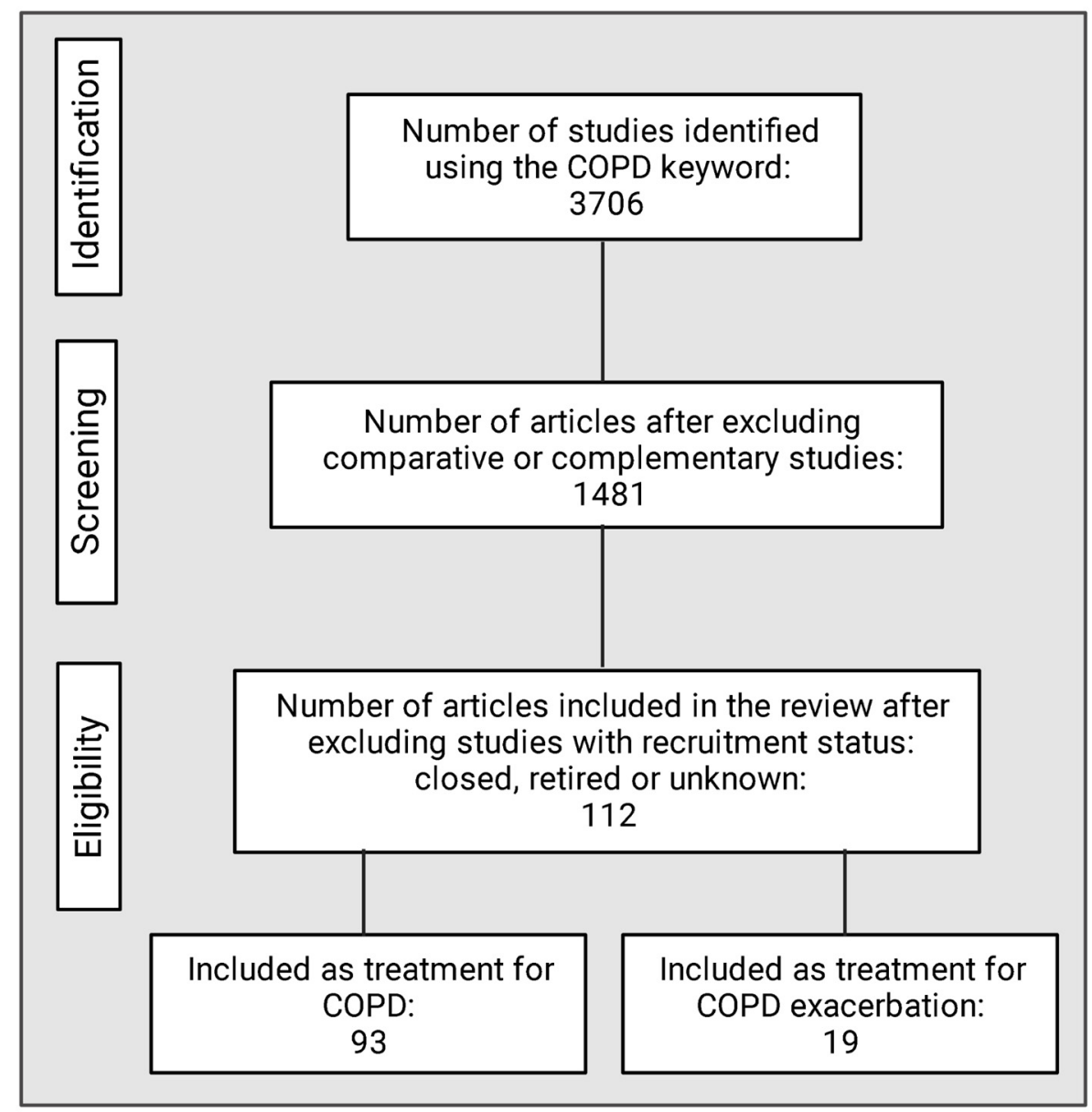

Figure 4. Research methodologies used to identify COPD treatments. Created with BioRender.com.

\section{Conclusions}

COPD presents a high mortality rate because it causes organ damage and alters lung function. An imbalance between oxidants and antioxidants is a primary characteristic of COPD. Oxidative stress plays a critical role in the inflammatory response in the lungs, leading to the activation of transcription factors that amplify the inflammatory response with cell infiltration and activation and inflammatory mediators' production. Current therapy consists of inhaled corticosteroids, bronchodilators, and both of them together. However, this is not fully effective in treating COPD or prevent exacerbations. Thus, studies aiming at the development or repurposing of new effective molecules are vital to treating COPD. Therapies to decrease oxidative stress and inflammation may improve lung function and increase patient survival. Herein, we discussed approaches focusing on prevention and treatment at a molecular level. Certain therapies, including various natural or synthetic antioxidants, can be effective because they can attenuate mucus hypersecretion, inflammation, matrix remodeling, and corticosteroid resistance. Current clinical and pre-clinical treatments under analysis include: (1) inhibitors of inflammatory mediators, phosphodiesterase, metalloprotease, neutrophil elastase, lipoxygenases, intracellular pathways (p38 MAPK, kinase inhibitor, and PI3K), EGFR, and HMG-CoA; (2) antagonist of mAChR, CRTH2, AT1R, CCR2, epithelial cells, sodium channels, CXCR2, bradykinin B1, and adenosine receptors; (3) new LAMA and LABA compounds; (4) agonists of ADRB2, lipocortin synthesis, RAR, and PPAR; and (5) stem cells therapies, immunostimulants, and gene therapies. The major challenge in COPD or exacerbation treatment is the diversity of COPD origin and time frame of intervention, too soon versus too late. Therefore, novel treatments focusing on antioxidant and anti-inflammatory activities, a new bronchodilator, 
a particular population cohort, targeting COPD at early or late stages, and lifestyle changes could provide new possibilities for the treatment or prevention of this noxious disease.

Author Contributions: Conceptualization, writing-original draft preparation and editing, and funding acquisition, S.d.O.R., C.M.C.d.C., G.M.V.S., P.L.S., A.R.S. and C.F.G.-d.-A.; Final approval, A.R.S. and C.F.G.-d.-A. All authors have read and agreed to the published version of the manuscript.

Funding: This research was funded by the Instituto Oswaldo Cruz, Fundação Oswaldo Cruz (FIOCRUZ), Coordenação de Aperfeiçoamento de Pessoal de Nível Superior (CAPES) Grant 001, Programa de Biotecnologia da Universidade Federal Fluminense (UFF), Universidade Federal do Estado do Rio de Janeiro (UNIRIO), Fundação Carlos Chagas Filho de Amparo à Pesquisa do Estado do Rio de Janeiro (FAPERJ), and the Conselho Nacional de Desenvolvimento Científico e Tecnológico (CNPq).

Institutional Review Board Statement: Not applicable.

Informed Consent Statement: Not applicable.

Data Availability Statement: Not applicable.

Conflicts of Interest: The authors declare no conflict of interest. The funders had no role in the design of the study; collection, analysis, or interpretation of data; in the writing of the manuscript; or in the decision to publish the results.

\section{References}

1. Mathers, C.D.; Loncar, D. Projections of Global Mortality and Burden of Disease from 2002 to 2030. PLoS Med. 2006, 3, e442. [CrossRef]

2. GOLD. Global Strategy for the Diagnosis, Management, and Prevention of Chronic Obstructive Pulmonary Disease 2021 Repost. Global Initiative for Chronic Obstructive Lung Disease-GOLD. 2021. Available online: https:/ / goldcopd.org/2021-gold-reports / (accessed on 30 August 2021).

3. Senior, R.M.; Anthonisen, N.R. Chronic Obstructive Pulmonary Disease (COPD). Am. J. Respir. Crit. Care Med. 1998, 157, S139-S147. [CrossRef]

4. Labaki, W.W.; Rosenberg, S.R. Chronic Obstructive Pulmonary Disease. Ann. Intern. Med. 2020, 173, ITC17-ITC32. [CrossRef]

5. Halpin, D.M.G.; Celli, B.R.; Criner, G.J.; Frith, P.; Varela, M.V.L.; Salvi, S.; Vogelmeier, C.F.; Chen, R.; Mortimer, K.; De Oca, M.M.; et al. The GOLD Summit on chronic obstructive pulmonary disease in low- and middle-income countries. Int. J. Tuberc. Lung Dis. 2019, 23, 1131-1141. [CrossRef]

6. Halbert, R.J.; Natoli, J.L.; Gano, A.; Badamgarav, E.; Buist, A.S.; Mannino, D. Global burden of COPD: Systematic review and meta-analysis. Eur. Respir. J. 2006, 28, 523-532. [CrossRef] [PubMed]

7. Barnes, P.J.; Burney, P.; Silverman, E.K.; Celli, B.R.; Vestbo, J.; Wedzicha, J.A.; Wouters, E.F.M. Chronic obstructive pulmonary disease. Nat. Rev. Dis. Prim. 2015, 1, 15076. [CrossRef]

8. Matsunaga, K.; Harada, M.; Suizu, J.; Oishi, K.; Asami-Noyama, M.; Hirano, T. Comorbid Conditions in Chronic Obstructive Pulmonary Disease: Potential Therapeutic Targets for Unmet Needs. J. Clin. Med. 2020, 9, 3078. [CrossRef] [PubMed]

9. Barnes, P.J. Chronic Obstructive Pulmonary Disease. N. Engl. J. Med. 2000, 343, 269-280. [CrossRef]

10. Celli, B.R. Predictors of mortality in COPD. Respir. Med. 2010, 104, 773-779. [CrossRef] [PubMed]

11. Gharib, S.A.; Manicone, A.M.; Parks, W.C. Matrix metalloproteinases in emphysema. Matrix Biol. 2018, 73, 34-51. [CrossRef]

12. Saetta, M.; Turato, G.; Maestrelli, P.; Mapp, C.E.; Fabbri, L.M. Cellular and Structural Bases of Chronic Obstructive Pulmonary Disease. Am. J. Respir. Crit. Care Med. 2001, 163, 1304-1309. [CrossRef]

13. De Oliveira, M.V.; Silva, P.L.; Rocco, P.R.M. Animal Models of Chronic Obstructive Pulmonary Disease Exacerbations: A Review of the Current Status. J. Biomed. Sci. 2016, 5. [CrossRef]

14. Kim, V.; Oros, M.; Durra, H.; Kelsen, S.; Aksoy, M.; Cornwell, W.D.; Rogers, T.J.; Criner, G.J. Chronic Bronchitis and Current Smoking Are Associated with More Goblet Cells in Moderate to Severe COPD and Smokers without Airflow Obstruction. PLoS ONE 2015, 10, e0116108. [CrossRef] [PubMed]

15. WHO. Chronic Obstructive Pulmonary Disease (COPD). Available online: https://www.who.int/news-room/fact-sheets/detail/ chronic-obstructive-pulmonary-disease-(copd) (accessed on 25 December 2020).

16. Adeloye, D.; Chua, S.; Lee, C.; Basquill, C.; Papana, A.; Theodoratou, E.; Nair, H.; Gasevic, D.; Sridhar, D.; Campbell, H.; et al. Global and regional estimates of COPD prevalence: Systematic review and meta-analysis. J. Glob. Health 2015, 5, 020415. [CrossRef]

17. Ruvuna, L.; Sood, A. Epidemiology of Chronic Obstructive Pulmonary Disease. Clin. Chest Med. 2020, 41, 315-327. [CrossRef] [PubMed]

18. Woldeamanuel, G.G.; Mingude, A.B.; Geta, T.G. Prevalence of chronic obstructive pulmonary disease (COPD) and its associated factors among adults in Abeshge District, Ethiopia: A cross sectional study. BMC Pulm. Med. 2019, 19, 181. [CrossRef] [PubMed] 
19. Stolbrink, M.; Mortimer, K. Collision of communicable and non-communicable disease epidemics-The case of HIV and COPD. Lancet Glob. Health 2018, 6, e126-e127. [CrossRef]

20. Rabe, K.F.; Watz, H. Chronic obstructive pulmonary disease. Lancet 2017, 389, 1931-1940. [CrossRef]

21. Lamprecht, B.; McBurnie, M.A.; Vollmer, W.M.; Gudmundsson, G.; Welte, T.; Nizankowska-Mogilnicka, E.; Studnicka, M.; Bateman, E.; Anto, J.M.; Burney, P.; et al. COPD in Never Smokers. Chest 2011, 139, 752-763. [CrossRef] [PubMed]

22. National Center for Health Statistics. Chronic Obstructive Pulmonary Disease (COPD) Includes: Chronic Bronchitis and Emphysema. Available online: https://www.cdc.gov/nchs/fastats/copd.htm (accessed on 17 March 2021).

23. Lopez, A.D.; Shibuya, K.; Rao, C.; Mathers, C.D.; Hansell, A.; Held, L.S.; Schmid, V.; Buist, S. Chronic obstructive pulmonary disease: Current burden and future projections. Eur. Respir. J. 2006, 27, 397-412. [CrossRef]

24. Wheaton, A.G.; Liu, Y.; Croft, J.B.; VanFrank, B.; Croxton, T.L.; Punturieri, A.; Postow, L.; Greenlund, K.J. Chronic Obstructive Pulmonary Disease and Smoking Status-United States, 2017. Morb. Mortal. Wkly. Rep. 2019, 68, 533-598. [CrossRef] [PubMed]

25. Nugmanova, D.; Feshchenko, Y.; Iashyna, L.; Gyrina, O.; Malynovska, K.; Mammadbayov, E.; Akhundova, I.; Nurkina, N.; Tariq, L.; Makarova, J.; et al. The prevalence, burden and risk factors associated with chronic obstructive pulmonary disease in Commonwealth of Independent States (Ukraine, Kazakhstan and Azerbaijan): Results of the CORE study. BMC Pulm. Med. 2018, 18, 26. [CrossRef]

26. Lange, P.; Ahmed, E.; Lahmar, Z.M.; Martinez, F.J.; Bourdin, A. Natural history and mechanisms of COPD. Respirology 2021, 26, 298-321. [CrossRef]

27. Duan, R.-R.; Hao, K.; Yang, T. Air pollution and chronic obstructive pulmonary disease. Chronic Dis. Transl. Med. 2020, 6, 260-269. [CrossRef] [PubMed]

28. Chapman, K.R.; Mannino, D.M.; Soriano, J.B.; Vermeire, P.A.; Buist, A.S.; Thun, M.J.; Connell, C.; Jemal, A.; Lee, T.A.; Miravitlles, M.; et al. Epidemiology and costs of chronic obstructive pulmonary disease. Eur. Respir. J. 2006, 27, 188-207. [CrossRef] [PubMed]

29. Ho, T.; Cusack, R.P.; Chaudhary, N.; Satia, I.; Kurmi, O.P. Under- and over-diagnosis of COPD: A global perspective. Breathe 2019, 15, 24-35. [CrossRef]

30. Ejaz, H.; Alsrhani, A.; Zafar, A.; Javed, H.; Junaid, K.; Abdalla, A.E.; Abosalif, K.O.; Ahmed, Z.; Younas, S. COVID-19 and comorbidities: Deleterious impact on infected patients. J. Infect. Public Health 2020, 13, 1833-1839. [CrossRef]

31. Olloquequi, J. COVID-19 Susceptibility in chronic obstructive pulmonary disease. Eur. J. Clin. Investig. 2020, 50, e13382. [CrossRef]

32. Halpin, D.M.G.; Criner, G.J.; Papi, A.; Singh, D.; Anzueto, A.; Martinez, F.J.; Agusti, A.A.; Vogelmeier, C.F. Global Initiative for the Diagnosis, Management, and Prevention of Chronic Obstructive Lung Disease. The 2020 GOLD Science Committee Report on COVID-19 and Chronic Obstructive Pulmonary Disease. Am. J. Respir. Crit. Care Med. 2021, 203, 24-36. [CrossRef]

33. Rocco, P.R.M.; Negri, E.M.; Kurtz, P.M.; Vasconcellos, F.P.; Silva, G.H.; Capelozzi, V.L.; Romero, P.V.; Zin, W.A. Lung Tissue Mechanics and Extracellular Matrix Remodeling in Acute Lung Injury. Am. J. Respir. Crit. Care Med. 2001, 164, $1067-1071$. [CrossRef]

34. Mecham, R.P. Elastin in lung development and disease pathogenesis. Matrix Biol. 2018, 73, 6-20. [CrossRef] [PubMed]

35. Burgstaller, G.; Oehrle, B.; Gerckens, M.; White, E.S.; Schiller, H.B.; Eickelberg, O. The instructive extracellular matrix of the lung: Basic composition and alterations in chronic lung disease. Eur. Respir. J. 2017, 50, 1601805. [CrossRef]

36. McDonough, J.; Yuan, R.; Suzuki, M.; Seyednejad, N.; Elliott, W.M.; Sanchez, P.G.; Wright, A.C.; Gefter, W.B.; Litzky, L.; Coxson, H.O.; et al. Small-Airway Obstruction and Emphysema in Chronic Obstructive Pulmonary Disease. N. Engl. J. Med. 2011, 365, 1567-1575. [CrossRef]

37. Wang, Y.; Xu, J.; Meng, Y.; Adcock, I.M.; Yao, X. Role of inflammatory cells in airway remodeling in COPD. Int. J. Chronic Obstr. Pulm. Dis. 2018, 13, 3341-3348. [CrossRef]

38. Lareau, S.C.; Fahy, B.; Meek, P.; Wang, A. Chronic Obstructive Pulmonary Disease (COPD). Am. J. Respir. Crit. Care Med. 2019, 199, P1-P2. [CrossRef]

39. Siddiqui, N.A.; Mansour, M.K.; Nookala, V. Bullous Emphysema. In StatPearls; StatPearls Publishing Copyright @ 2021; StatPearls Publishing LLC.: Treasure Island, FL, USA, 2021.

40. Pahal, P.; Avula, A.; Sharma, S. Emphysema. In StatPearls; StatPearls Publishing Copyright @ 2021; StatPearls Publishing LLC.: Treasure Island, FL, USA, 2021.

41. Houghton, A.M. Matrix metalloproteinases in destructive lung disease. Matrix Biol. 2015, 44-46, 167-174. [CrossRef] [PubMed]

42. Hendrix, A.Y.; Kheradmand, F. The Role of Matrix Metalloproteinases in Development, Repair, and Destruction of the Lungs. Prog. Mol. Biol. Transl. Sci. 2017, 148, 1-29. [CrossRef]

43. Marchioni, A.; Tonelli, R.; Fantini, R.; Tabbì, L.; Castaniere, I.; Livrieri, F.; Bedogni, S.; Ruggieri, V.; Pisani, L.; Nava, S.; et al. Respiratory Mechanics and Diaphragmatic Dysfunction in COPD Patients Who Failed Non-Invasive Mechanical Ventilation. Int. J. Chronic Obstr. Pulm. Dis. 2019, 14, 2575-2585. [CrossRef]

44. Sharma, B.B.; Singh, V. Diaphragmatic dysfunction in chronic obstructive pulmonary disease. Lung India 2019, 36, 285-287. [CrossRef] [PubMed]

45. Kim, W.Y.; Suh, H.J.; Hong, S.-B.; Koh, Y.; Lim, C.-M. Diaphragm dysfunction assessed by ultrasonography: Influence on weaning from mechanical ventilation*. Crit. Care Med. 2011, 39, 2627-2630. [CrossRef]

46. Samanta, S.; Singh, R.K.; Baronia, A.K.; Poddar, B.; Azim, A.; Gurjar, M. Diaphragm thickening fraction to predict weaning-a prospective exploratory study. J. Intensive Care 2017, 5, 62. [CrossRef] 
47. Gan, W.Q.; Man, S.F.P.; Senthilselvan, A.; Sin, D.D. Association between chronic obstructive pulmonary disease and systemic inflammation: A systematic review and a meta-analysis. Thorax 2004, 59, 574-580. [CrossRef] [PubMed]

48. Meduri, G.U.; Annane, D.; Chrousos, G.P.; Marik, P.E.; Sinclair, S.E. Activation and Regulation of Systemic Inflammation in ARDS. Chest 2009, 136, 1631-1643. [CrossRef] [PubMed]

49. Barreiro, E.; de la Puente, B.; Minguella, J.; Corominas, J.M.; Serrano, S.; Hussain, S.N.A.; Gea, J. Oxidative Stress and Respiratory Muscle Dysfunction in Severe Chronic Obstructive Pulmonary Disease. Am. J. Respir. Crit. Care Med. 2005, 171, 1116-1124. [CrossRef]

50. Ottenheijm, C.A.C.; Heunks, L.M.A.; Dekhuijzen, P.N.R. Diaphragm Muscle Fiber Dysfunction in Chronic Obstructive Pulmonary Disease. Am. J. Respir. Crit. Care Med. 2007, 175, 1233-1240. [CrossRef]

51. De Troyer, A.; Wilson, T.A. Effect of acute inflation on the mechanics of the inspiratory muscles. J. Appl. Physiol. 2009, 107, 315-323. [CrossRef] [PubMed]

52. Picard, M.; McManus, M.J.; Gray, J.D.; Nasca, C.; Moffat, C.; Kopinski, P.K.; Seifert, E.L.; McEwen, B.S.; Wallace, D.C. Mitochondrial functions modulate neuroendocrine, metabolic, inflammatory, and transcriptional responses to acute psychological stress. Proc. Natl. Acad. Sci. USA 2015, 112, E6614-E6623. [CrossRef] [PubMed]

53. Khosravi, S.; Harner, M.E. The MICOS complex, a structural element of mitochondria with versatile functions. Biol. Chem. 2020, 401, 765-778. [CrossRef] [PubMed]

54. Hoppins, S.; Collins, S.; Cassidy-Stone, A.; Hummel, E.; DeVay, R.M.; Lackner, L.L.; Westermann, B.; Schuldiner, M.; Weissman, J.S.; Nunnari, J. A mitochondrial-focused genetic interaction map reveals a scaffold-like complex required for inner membrane organization in mitochondria. J. Cell Biol. 2011, 195, 323-340. [CrossRef] [PubMed]

55. Chen, H.; Vermulst, M.; Wang, Y.E.; Chomyn, A.; Prolla, T.A.; McCaffery, J.M.; Chan, D.C. Mitochondrial Fusion Is Required for mtDNA Stability in Skeletal Muscle and Tolerance of mtDNA Mutations. Cell 2010, 141, 280-289. [CrossRef] [PubMed]

56. Benard, G.; Bellance, N.; Jose, C.; Melser, S.; Nouette-Gaulain, K.; Rossignol, R. Multi-site control and regulation of mitochondrial energy production. Biochim. et Biophys. Acta (BBA) Bioenerg. 2010, 1797, 698-709. [CrossRef] [PubMed]

57. Taguchi, N.; Ishihara, N.; Jofuku, A.; Oka, T.; Mihara, K. Mitotic Phosphorylation of Dynamin-related GTPase Drp1 Participates in Mitochondrial Fission. J. Biol. Chem. 2007, 282, 11521-11529. [CrossRef] [PubMed]

58. Lee, Y.; Lee, H.-Y.; Hanna, R.A.; Gustafsson, Å.B. Mitochondrial autophagy by Bnip3 involves Drp1-mediated mitochondrial fission and recruitment of Parkin in cardiac myocytes. Am. J. Physiol. Heart Circ. Physiol. 2011, 301, H1924-H1931. [CrossRef]

59. Gao, F.; Reynolds, M.B.; Passalacqua, K.D.; Sexton, J.Z.; Abuaita, B.H.; O’Riordan, M.X.D. The Mitochondrial Fission Regulator DRP1 Controls Post-Transcriptional Regulation of TNF- $\alpha$. Front. Cell. Infect. Microbiol. 2021, 10. [CrossRef]

60. Horn, A.; Raavicharla, S.; Shah, S.; Cox, D.; Jaiswal, J.K. Mitochondrial fragmentation enables localized signaling required for cell repair. J. Cell Biol. 2020, 219, e201909154. [CrossRef]

61. Dai, W.; Jiang, L. Dysregulated Mitochondrial Dynamics and Metabolism in Obesity, Diabetes, and Cancer. Front. Endocrinol. 2019, 10, 570. [CrossRef] [PubMed]

62. Blanco, I.; Tura-Ceide, O.; Peinado, V.I.; Barberà, J.A. Updated Perspectives on Pulmonary Hypertension in COPD. Int. J. Chronic Obstr. Pulm. Dis. 2020, 15, 1315-1324. [CrossRef]

63. Opitz, I.; Ulrich, S. Pulmonary hypertension in chronic obstructive pulmonary disease and emphysema patients: Prevalence, therapeutic options and pulmonary circulatory effects of lung volume reduction surgery. J. Thorac. Dis. 2018, 10, S2763-S2774 [CrossRef]

64. Mathioudakis, A.G.; Janssens, W.; Sivapalan, P.; Singanayagam, A.; Dransfield, M.T.; Jensen, J.-U.S.; Vestbo, J. Acute exacerbations of chronic obstructive pulmonary disease: In search of diagnostic biomarkers and treatable traits. Thorax 2020, 75, 520-527. [CrossRef]

65. Bouquet, J.; Tabor, D.E.; Silver, J.S.; Nair, V.; Tovchigrechko, A.; Griffin, M.P.; Esser, M.T.; Sellman, B.R.; Jin, H. Microbial burden and viral exacerbations in a longitudinal multicenter COPD cohort. Respir. Res. 2020, 21, 77. [CrossRef]

66. Tuder, R.M. Pulmonary vascular remodeling in pulmonary hypertension. Cell Tissue Res. 2017, 367, 643-649. [CrossRef]

67. Bós, D.D.S.G.; Van Der Bruggen, C.E.E.; Kurakula, K.; Sun, X.-Q.; Casali, K.R.; Casali, A.G.; Rol, N.; Szulcek, R.; Dos Remedios, C.; Guignabert, C.; et al. Contribution of Impaired Parasympathetic Activity to Right Ventricular Dysfunction and Pulmonary Vascular Remodeling in Pulmonary Arterial Hypertension. Circulation 2018, 137, 910-924. [CrossRef]

68. Humbert, M.; Guignabert, C.; Bonnet, S.; Dorfmüller, P.; Klinger, J.R.; Nicolls, M.R.; Olschewski, A.J.; Pullamsetti, S.S.; Schermuly, R.T.; Stenmark, K.R.; et al. Pathology and pathobiology of pulmonary hypertension: State of the art and research perspectives. Eur. Respir. J. 2019, 53, 1801887. [CrossRef] [PubMed]

69. Sparks, M.A.; Makhanova, N.A.; Griffiths, R.C.; Snouwaert, J.N.; Koller, B.H.; Coffman, T.M. Thromboxane Receptors in Smooth Muscle Promote Hypertension, Vascular Remodeling, and Sudden Death. Hypertension 2013, 61, 166-173. [CrossRef] [PubMed]

70. Fischer, B.; Voynow, J.; Ghio, A. COPD: Balancing oxidants and antioxidants. Int. J. Chronic Obstr. Pulm. Dis. 2015, 10, 261-276. [CrossRef]

71. MacNee, W. ABC of chronic obstructive pulmonary disease. Pathology, pathogenesis, and pathophysiology. BMJ 2006, 332, 1202-1204. [CrossRef]

72. Austin, V.; Crack, P.; Bozinovski, S.; Miller, A.A.; Vlahos, R. COPD and stroke: Are systemic inflammation and oxidative stress the missing links? Clin. Sci. 2016, 130, 1039-1050. [CrossRef] [PubMed] 
73. Rahman, I. Pharmacological antioxidant strategies as therapeutic interventions for COPD. Biochim. Biophys. Acta (BBA) Mol. Basis Dis. 2012, 1822, 714-728. [CrossRef]

74. Schuliga, M. NF-kappaB Signaling in Chronic Inflammatory Airway Disease. Biomolecules 2015, 5, 1266-1283. [CrossRef]

75. Rahman, I.; MacNee, W. Antioxidant pharmacological therapies for COPD. Curr. Opin. Pharmacol. 2012, 12, 256-265. [CrossRef]

76. Marginean, C.; Popescu, M.S.; Vladaia, M.; Tudorascu, D.; Pirvu, D.C.; Petrescu, F. Involvement of Oxidative Stress in COPD. Curr. Health Sci. J. 2018, 44, 48-54. [CrossRef]

77. Liu, Q.; Gao, Y.; Ci, X. Role of Nrf2 and Its Activators in Respiratory Diseases. Oxidative Med. Cell. Longev. 2019, 2019. [CrossRef]

78. Vlahos, R.; Bozinovski, S. Recent advances in pre-clinical mouse models of COPD. Clin. Sci. 2013, 126, 253-265. [CrossRef] [PubMed]

79. Bautista, M.V.; Chen, Y.; Ivanova, V.S.; Rahimi, M.K.; Watson, A.M.; Rose, M.C. IL-8 Regulates Mucin Gene Expression at the Posttranscriptional Level in Lung Epithelial Cells. J. Immunol. 2009, 183, 2159-2166. [CrossRef]

80. Inui, T.; Watanabe, M.; Nakamoto, K.; Sada, M.; Hirata, A.; Nakamura, M.; Honda, K.; Ogawa, Y.; Takata, S.; Yokoyama, T.; et al. Bronchial epithelial cells produce CXCL1 in response to LPS and TNF $\alpha$ : A potential role in the pathogenesis of COPD. Exp. Lung Res. 2018, 44, 323-331. [CrossRef]

81. Shukla, S.D.; Mahmood, M.Q.; Weston, S.; Latham, R.; Muller, H.K.; Sohal, S.S.; Walters, E.H. The main rhinovirus respiratory tract adhesion site (ICAM-1) is upregulated in smokers and patients with chronic airflow limitation (CAL). Respir. Res. 2017, 18, 6. [CrossRef] [PubMed]

82. Kucich, U.; Christner, P.; Lippmann, M.; Fein, A.; Goldberg, A.; Kimbel, P.; Weinbaum, G.; Rosenbloom, J. Immunologic measurement of elastin-derived peptides in human serum. Am. Rev. Respir. Dis. 1983, 127, S28-S30. [CrossRef] [PubMed]

83. Lam, D.C.; Chan, S.C.; Mak, J.C.; Freeman, C.; Ip, M.S.; Shum, D.K. S-maltoheptaose targets syndecan-bound effectors to reduce smoking-related neutrophilic inflammation. Sci. Rep. 2015, 5, 12945. [CrossRef] [PubMed]

84. Jeffery, P.K. Remodeling and Inflammation of Bronchi in Asthma and Chronic Obstructive Pulmonary Disease; American Thoracic Society: New York, NY, USA, 2004; Volume 1, pp. 176-183.

85. Linden, S.K.; Sutton, P.; Karlsson, N.G.; Korolik, V.; McGuckin, M.A. Mucins in the mucosal barrier to infection. Mucosal Immunol. 2008, 1, 183-197. [CrossRef] [PubMed]

86. Rogers, D.F. Airway mucus hypersecretion in asthma: An undervalued pathology? Curr. Opin. Pharmacol. 2004, 4, 241-250. [CrossRef]

87. Wedzicha, J. Airway Mucins in Chronic Obstructive Pulmonary Disease. N. Engl. J. Med. 2017, 377, 986-987. [CrossRef]

88. Brusselle, G.G.; Joos, G.F.; Bracke, K.R. New insights into the immunology of chronic obstructive pulmonary disease. Lancet 2011, 378, 1015-1026. [CrossRef]

89. Gao, W.; Li, L.; Wang, Y.; Zhang, S.; Adcock, I.; Barnes, P.J.; Huang, M.; Yao, X. Bronchial epithelial cells: The key effector cells in the pathogenesis of chronic obstructive pulmonary disease? Respirology 2015, 20, 722-729. [CrossRef] [PubMed]

90. Barnes, P.J. Inflammatory mechanisms in patients with chronic obstructive pulmonary disease. J. Allergy Clin. Immunol. 2016, 138, 16-27. [CrossRef] [PubMed]

91. Kanazawa, H.; Tochino, Y.; Asai, K.; Hirata, K. Simultaneous Assessment of Hepatocyte Growth Factor and Vascular Endothelial Growth Factor in Epithelial Lining Fluid From Patients With COPD. Chest 2014, 146, 1159-1165. [CrossRef] [PubMed]

92. Saito, A.; Horie, M.; Nagase, T. TGF- $\beta$ Signaling in Lung Health and Disease. Int. J. Mol. Sci. 2018, 19, 2460. [CrossRef]

93. Wang, X.; Khalil, R.A. Matrix Metalloproteinases, Vascular Remodeling, and Vascular Disease. Adv. Pharmacol. 2018, 81, 241-330. [CrossRef] [PubMed]

94. Zhao, C.-Z.; Fang, X.-C.; Wang, D.; Tang, F.-D.; Wang, X.-D. Involvement of type II pneumocytes in the pathogenesis of chronic obstructive pulmonary disease. Respir. Med. 2010, 104, 1391-1395. [CrossRef] [PubMed]

95. Shokolenko, I.; Venediktova, N.; Bochkareva, A.; Wilson, G.L.; Alexeyev, M.F. Oxidative stress induces degradation of mitochondrial DNA. Nucleic Acids Res. 2009, 37, 2539-2548. [CrossRef]

96. Wiegman, C.H.; Michaeloudes, C.; Haji, G.; Narang, P.; Clarke, C.J.; Russell, K.E.; Bao, W.; Pavlidis, S.; Barnes, P.J.; Kanerva, J.; et al. Oxidative stress-induced mitochondrial dysfunction drives inflammation and airway smooth muscle remodeling in patients with chronic obstructive pulmonary disease. J. Allergy Clin. Immunol. 2015, 136, 769-780. [CrossRef]

97. Wu, K.; Luan, G.; Xu, Y.; Shen, S.; Qian, S.; Zhu, Z.; Zhang, X.; Yin, S.; Ye, J. Cigarette smoke extract increases mitochondrial membrane permeability through activation of adenine nucleotide translocator (ANT) in lung epithelial cells. Biochem. Biophys. Res. Commun. 2020, 525, 733-739. [CrossRef]

98. Anseth, J.W.; Goffin, A.J.; Fuller, G.G.; Ghio, A.J.; Kao, P.N.; Upadhyay, D. Lung Surfactant Gelation Induced by Epithelial Cells Exposed to Air Pollution or Oxidative Stress. Am. J. Respir. Cell Mol. Biol. 2005, 33, 161-168. [CrossRef] [PubMed]

99. Lommatzsch, M.; Cicko, S.; Müller, T.; Lucattelli, M.; Bratke, K.; Stoll, P.; Grimm, M.; Dürk, T.; Zissel, G.; Ferrari, D.; et al. Extracellular Adenosine Triphosphate and Chronic Obstructive Pulmonary Disease. Am. J. Respir. Crit. Care Med. 2010, 181, 928-934. [CrossRef] [PubMed]

100. Shaykhiev, R.; Otaki, F.; Bonsu, P.; Dang, D.T.; Teater, M.; Strulovici-Barel, Y.; Salit, J.; Harvey, B.-G.; Crystal, R.G. Cigarette smoking reprograms apical junctional complex molecular architecture in the human airway epithelium in vivo. Cell. Mol. Life Sci. 2011, 68, 877-892. [CrossRef] [PubMed] 
101. Comstock, A.T.; Ganesan, S.; Chattoraj, A.; Faris, A.N.; Margolis, B.L.; Hershenson, M.B.; Sajjan, U.S. Rhinovirus-Induced Barrier Dysfunction in Polarized Airway Epithelial Cells Is Mediated by NADPH Oxidase 1. J. Virol. 2011, 85, 6795-6808. [CrossRef] [PubMed]

102. Goldkorn, T.; Filosto, S. Lung Injury and Cancer. Am. J. Respir. Cell Mol. Biol. 2010, 43, 259-268. [CrossRef]

103. Yang, T.; Luo, F.; Shen, Y.; An, J.; Li, X.; Liu, X.; Ying, B.; Liao, Z.; Dong, J.; Guo, L.; et al. Quercetin attenuates airway inflammation and mucus production induced by cigarette smoke in rats. Int. Immunopharmacol. 2012, 13, 73-81. [CrossRef]

104. Anagnostis, A.; Neofytou, E.; Soulitzis, N.; Kampas, D.; Drositis, I.; Dermitzaki, D.; Tzanakis, N.; Schiza, S.; Siafakas, N.M.; Tzortzaki, E.G. Molecular profiling of EGFR family in chronic obstructive pulmonary disease: Correlation with airway obstruction. Eur. J. Clin. Investig. 2013, 43, 1299-1306. [CrossRef] [PubMed]

105. Ridley, C.; Thornton, D.J. Mucins: The frontline defence of the lung. Biochem. Soc. Trans. 2018, 46, 1099-1106. [CrossRef]

106. Fujisawa, T.; Chang, M.M.-J.; Velichko, S.; Thai, P.; Hung, L.-Y.; Huang, F.; Phuong, N.; Chen, Y.; Wu, R. NF-kB Mediates IL-1 $\beta-$ and IL-17A-InducedMUC5BExpression in Airway Epithelial Cells. Am. J. Respir. Cell Mol. Biol. 2011, 45, 246-252. [CrossRef] [PubMed]

107. Kesimer, M.; Ford, A.A.; Ceppe, A.; Radicioni, G.; Cao, R.; Davis, C.W.; Doerschuk, C.M.; Alexis, N.E.; Anderson, W.H.; Henderson, A.G.; et al. Airway Mucin Concentration as a Marker of Chronic Bronchitis. N. Engl. J. Med. 2017, 377, 911-922. [CrossRef]

108. Lin, V.Y.; Kaza, N.; Birket, S.E.; Kim, H.; Edwards, L.; Lafontaine, J.; Liu, L.; Mazur, M.; Byzek, S.A.; Hanes, J.; et al. Excess mucus viscosity and airway dehydration impact COPD airway clearance. Eur. Respir. J. 2019, 55, 1900419. [CrossRef] [PubMed]

109. Russell, R.; Thorley, A.; Culpitt, S.V.; Dodd, S.; Donnelly, L.; Demattos, C.; Fitzgerald, M.; Barnes, P.J. Alveolar macrophagemediated elastolysis: Roles of matrix metalloproteinases, cysteine, and serine proteases. Am. J. Physiol. Cell. Mol. Physiol. 2002, 283, L867-L873. [CrossRef]

110. Bernardo, I.; Bozinovski, S.; Vlahos, R. Targeting oxidant-dependent mechanisms for the treatment of COPD and its comorbidities. Pharmacol. Ther. 2015, 155, 60-79. [CrossRef]

111. Trocme, C.; Deffert, C.; Cachat, J.; Donati, Y.; Tissot, C.; Papacatzis, S.; Braunersreuther, V.; Pache, J.-C.; Krause, K.-H.; Holmdahl, R.; et al. Macrophage-specific NOX2 contributes to the development of lung emphysema through modulation of SIRT1/MMP-9 pathways. J. Pathol. 2014, 235, 65-78. [CrossRef]

112. Atri, C.; Guerfali, F.Z.; Laouini, D. Role of Human Macrophage Polarization in Inflammation during Infectious Diseases. Int. J. Mol. Sci. 2018, 19, 1801. [CrossRef]

113. Parisi, L.; Gini, E.; Baci, D.; Tremolati, M.; Fanuli, M.; Bassani, B.; Farronato, G.; Bruno, A.; Mortara, L. Macrophage Polarization in Chronic Inflammatory Diseases: Killers or Builders? J. Immunol. Res. 2018, 2018. [CrossRef]

114. Vlahos, R. Role of alveolar macrophages in chronic obstructive pulmonary disease. Front. Immunol. 2014, 5, 435. [CrossRef] [PubMed]

115. Chana, K.K.; Fenwick, P.S.; Nicholson, A.G.; Barnes, P.J.; Donnelly, L.E. Identification of a distinct glucocorticosteroid-insensitive pulmonary macrophage phenotype in patients with chronic obstructive pulmonary disease. J. Allergy Clin. Immunol. 2014, 133, 207-216.e11. [CrossRef]

116. Traves, S.L.; Culpitt, S.V.; Russell, R.; Barnes, P.J.; Donnelly, L. Increased levels of the chemokines GROalpha and MCP-1 in sputum samples from patients with COPD. Thorax 2002, 57, 590-595. [CrossRef]

117. Yamasaki, K.; Van Eeden, S.F. Lung Macrophage Phenotypes and Functional Responses: Role in the Pathogenesis of COPD. Int. J. Mol. Sci. 2018, 19, 582. [CrossRef]

118. Belchamber, K.B.; Singh, R.; Batista, C.M.; Whyte, M.K.; Dockrell, D.H.; Kilty, I.; Robinson, M.J.; Wedzicha, J.; Barnes, P.J.; Donnelly, L.E. Defective bacterial phagocytosis is associated with dysfunctional mitochondria in COPD macrophages. Eur. Respir. J. 2019, 54, 1802244. [CrossRef] [PubMed]

119. Naito, K.; Yamasaki, K.; Yatera, K.; Akata, K.; Noguchi, S.; Kawanami, T.; Fukuda, K.; Kido, T.; Ishimoto, H.; Mukae, H. Bacteriological incidence in pneumonia patients with pulmonary emphysema: A bacterial floral analysis using the $16 \mathrm{~S}$ ribosomal RNA gene in bronchoalveolar lavage fluid. Int. J. Chronic Obstr. Pulm. Dis. 2017, 12, 2111-2120. [CrossRef]

120. Kirkham, P.A.; Barnes, P.J. Oxidative Stress in COPD. Chest 2013, 144, 266-273. [CrossRef]

121. Shibata, S.; Miyake, K.; Tateishi, T.; Yoshikawa, S.; Yamanishi, Y.; Miyazaki, Y.; Inase, N.; Karasuyama, H. Basophils trigger emphysema development in a murine model of COPD through IL-4-mediated generation of MMP-12-producing macrophages. Proc. Natl. Acad. Sci. USA 2018, 115, 13057-13062. [CrossRef] [PubMed]

122. Akata, K.; Van Eeden, S.F. Lung Macrophage Functional Properties in Chronic Obstructive Pulmonary Disease. Int. J. Mol. Sci. 2020, 21, 853. [CrossRef]

123. Guiedem, E.; Ikomey, G.M.; Nkenfou, C.; Walter, P.-Y.E.; Mesembe, M.; Chegou, N.N.; Jacobs, G.B.; Assoumou, M.C.O. Chronic obstructive pulmonary disease (COPD): Neutrophils, macrophages and lymphocytes in patients with anterior tuberculosis compared to tobacco related COPD. BMC Res. Notes 2018, 11, 192. [CrossRef]

124. Di Stefano, A.; Caramori, G.; Gnemmi, I.; Contoli, M.; Vicari, C.; Capelli, A.; Magno, F.; D’Anna, S.E.; Zanini, A.; Brun, P.; et al. T helper type 17-related cytokine expression is increased in the bronchial mucosa of stable chronic obstructive pulmonary disease patients. Clin. Exp. Immunol. 2009, 157, 316-324. [CrossRef]

125. Grundy, S.; Plumb, J.; Lea, S.; Kaur, M.; Ray, D.; Singh, D. Down Regulation of T Cell Receptor Expression in COPD Pulmonary CD8 Cells. PLoS ONE 2013, 8, e71629. [CrossRef] 
126. Hodge, G.; Nairn, J.; Holmes, M.; Reynolds, P.N.; Hodge, S. Increased intracellular T helper 1 proinflammatory cytokine production in peripheral blood, bronchoalveolar lavage and intraepithelial T cells of COPD subjects. Clin. Exp. Immunol. 2007, 150, 22-29. [CrossRef]

127. Hodge, G.; Mukaro, V.; Reynolds, P.N.; Hodge, S. Role of increased CD8/CD28 $8^{\text {null }} \mathrm{T}$ cells and alternative co-stimulatory molecules in chronic obstructive pulmonary disease. Clin. Exp. Immunol. 2011, 166, 94-102. [CrossRef] [PubMed]

128. Demedts, I.K.; Demoor, T.; Bracke, K.R.; Joos, G.F.; Brusselle, G.G. Role of apoptosis in the pathogenesis of COPD and pulmonary emphysema. Respir. Res. 2006, 7, 53. [CrossRef]

129. Dumitriu, I.E. The life (and death) of $\mathrm{CD}^{+} \mathrm{CD} 28^{\text {null }} \mathrm{T}$ cells in inflammatory diseases. Immunology 2015, 146, 185-193. [CrossRef] [PubMed]

130. Lambers, C.; Hacker, S.; Posch, M.; Hoetzenecker, K.; Pollreisz, A.; Lichtenauer, M.; Klepetko, W.; Ankersmit, H.J. T cell senescence and contraction of $\mathrm{T}$ cell repertoire diversity in patients with chronic obstructive pulmonary disease. Clin. Exp. Immunol. 2009, 155, 466-475. [CrossRef] [PubMed]

131. Hodge, G.; Hodge, S. Steroid Resistant CD8 ${ }^{+} C D 28^{\text {null }}$ NKT-Like Pro-inflammatory Cytotoxic Cells in Chronic Obstructive Pulmonary Disease. Front. Immunol. 2016, 7, 617. [CrossRef]

132. Hodge, G.; Jersmann, H.; Tran, H.B.; Roscioli, E.; Holmes, M.; Reynolds, P.N.; Hodge, S. Lymphocyte senescence in COPD is associated with decreased histone deacetylase 2 expression by pro-inflammatory lymphocytes. Respir. Res. 2015, 16, 130. [CrossRef] [PubMed]

133. Baniyash, M. TCR ל-chain downregulation: Curtailing an excessive inflammatory immune response. Nat. Rev. Immunol. 2004, 4, 675-687. [CrossRef]

134. Okeke, E.B.; Uzonna, J.E. The Pivotal Role of Regulatory T Cells in the Regulation of Innate Immune Cells. Front. Immunol. 2019, 10, 680. [CrossRef]

135. Li, Z.; Li, D.; Tsun, A.; Li, B. FOXP3+ regulatory T cells and their functional regulation. Cell. Mol. Immunol. 2015, 12, 558-565. [CrossRef]

136. Kalathil, S.G.; Lugade, A.A.; Pradhan, V.; Miller, A.; Parameswaran, G.I.; Sethi, S.; Thanavala, Y. T-Regulatory Cells and Programmed Death 1+T Cells Contribute to Effector T-Cell Dysfunction in Patients with Chronic Obstructive Pulmonary Disease. Am. J. Respir. Crit. Care Med. 2014, 190, 40-50. [CrossRef]

137. Olloquequi, J.; Ferrer, J.; Montes, J.F.; Rodríguez, E.; Montero, M.A.; García-Valero, J. Differential lymphocyte infiltration in small airways and lung parenchyma in COPD patients. Respir. Med. 2010, 104, 1310-1318. [CrossRef] [PubMed]

138. Seys, L.J.M.; Verhamme, F.M.; Schinwald, A.; Hammad, H.; Cunoosamy, D.M.; Bantsimba-Malanda, C.; Sabirsh, A.; McCall, E.; Flavell, L.; Herbst, R.; et al. Role of B Cell-Activating Factor in Chronic Obstructive Pulmonary Disease. Am. J. Respir. Crit. Care Med. 2015, 192, 706-718. [CrossRef] [PubMed]

139. Kirkham, P.A.; Caramori, G.; Casolari, P.; Papi, A.; Edwards, M.; Shamji, B.; Triantaphyllopoulos, K.; Hussain, F.; Pinart, M.; Khan, Y.; et al. Oxidative Stress-induced Antibodies to Carbonyl-modified Protein Correlate with Severity of Chronic Obstructive Pulmonary Disease. Am. J. Respir. Crit. Care Med. 2011, 184, 796-802. [CrossRef] [PubMed]

140. Lee, S.-H.; Goswami, S.; Grudo, A.; Song, L.-Z.; Bandi, V.; Goodnight-White, S.; Green, L.; Hacken-Bitar, J.; Huh, J.; Bakaeen, F.; et al. Antielastin autoimmunity in tobacco smoking-induced emphysema. Nat. Med. 2007, 13, 567-569. [CrossRef]

141. Wen, L.; Krauss-Etschmann, S.; Petersen, F.; Yu, X. Autoantibodies in Chronic Obstructive Pulmonary Disease. Front. Immunol. 2018, 9, 66. [CrossRef]

142. Klareskog, L.; Catrina, A.I. Lungs and citrullination. Nat. Rev. Rheumatol. 2015, 11, 261-262. [CrossRef] [PubMed]

143. Olloquequi, J.; Montes, J.F.; Prats, A.; Rodriguez, E.; Montero, M.A.; Garcia-Valero, J.; Ferrer, J. Significant increase of CD57+ cells in pulmonary lymphoid follicles of COPD patients. Eur. Respir. J. 2010, 37, 289-298. [CrossRef]

144. Sullivan, J.-L.; Bagevalu, B.; Glass, C.; Sholl, L.; Kraft, M.; Martinez, F.D.; Bastarrika, G.; de Torres, J.P.; Estepar, R.S.J.; Guerra, S.; et al. B Cell-Adaptive Immune Profile in Emphysema-Predominant Chronic Obstructive Pulmonary Disease. Am. J. Respir. Crit. Care Med. 2019, 200, 1434-1439. [CrossRef]

145. Pascoe, S.J.; Papi, A.; Midwinter, D.; Lettis, S.; Barnes, N. Circulating neutrophils levels are a predictor of pneumonia risk in chronic obstructive pulmonary disease. Respir. Res. 2019, 20, 195. [CrossRef] [PubMed]

146. Caramori, G.; Casolari, P.; Barczyk, A.; Durham, A.L.; Di Stefano, A.; Adcock, I. COPD immunopathology. Semin. Immunopathol. 2016, 38, 497-515. [CrossRef]

147. Lee, H.; Um, S.-J.; Kim, Y.S.; Kim, D.K.; Jang, A.S.; Choi, H.S.; Kim, Y.H.; Kim, T.E.; Yoo, K.H.; Jung, K.-S. Association of the Neutrophil-to-Lymphocyte Ratio with Lung Function and Exacerbations in Patients with Chronic Obstructive Pulmonary Disease. PLoS ONE 2016, 11, e0156511. [CrossRef]

148. Paliogiannis, P.; Fois, A.G.; Sotgia, S.; Mangoni, A.A.; Zinellu, E.; Pirina, P.; Negri, S.; Carru, C.; Zinellu, A. Neutrophil to lymphocyte ratio and clinical outcomes in COPD: Recent evidence and future perspectives. Eur. Respir. Rev. 2018, $27,170113$. [CrossRef] [PubMed]

149. Zhang, X.; Zheng, H.; Zhang, H.; Ma, W.; Wang, F.; Liu, C.; He, S. Increased interleukin (IL)-8 and decreased IL-17 production in chronic obstructive pulmonary disease (COPD) provoked by cigarette smoke. Cytokine 2011, 56, 717-725. [CrossRef]

150. Strzelak, A.; Ratajczak, A.; Adamiec, A.; Feleszko, W. Tobacco Smoke Induces and Alters Immune Responses in the Lung Triggering Inflammation, Allergy, Asthma and Other Lung Diseases: A Mechanistic Review. Int. J. Environ. Res. Public Health 2018, 15, 1033. [CrossRef] 
151. Takahashi, T.; Kobayashi, S.; Fujino, N.; Suzuki, T.; Ota, C.; He, M.; Yamada, M.; Suzuki, S.; Yanai, M.; Kurosawa, S.; et al. Increased circulating endothelial microparticles in COPD patients: A potential biomarker for COPD exacerbation susceptibility. Thorax 2012, 67, 1067-1074. [CrossRef] [PubMed]

152. Zhu, A.; Ge, D.; Zhang, J.; Teng, Y.; Yuan, C.; Huang, M.; Adcock, I.M.; Barnes, P.J.; Yao, X. Sputum myeloperoxidase in chronic obstructive pulmonary disease. Eur. J. Med Res. 2014, 19, 12. [CrossRef] [PubMed]

153. Vlahos, R.; Wark, P.; Anderson, G.P.; Bozinovski, S. Glucocorticosteroids Differentially Regulate MMP-9 and Neutrophil Elastase in COPD. PLoS ONE 2012, 7, e33277. [CrossRef]

154. Liu, T.; Wang, F.-P.; Wang, G.; Mao, H. Role of Neutrophil Extracellular Traps in Asthma and Chronic Obstructive Pulmonary Disease. Chin. Med. J. 2017, 130, 730-736. [CrossRef]

155. Porto, B.N.; Stein, R. Neutrophil Extracellular Traps in Pulmonary Diseases: Too Much of a Good Thing? Front. Immunol. 2016, 7, 311. [CrossRef]

156. Noguera, A.; Batle, S.; Miralles, C.; Iglesias, J.; Busquets, X.; MacNee, W.; Agusti, A. G Enhanced neutrophil response in chronic obstructive pulmonary disease. Thorax 2001, 56, 432-437. [CrossRef]

157. Milara, J.; Juan, G.; Peiró, T.; Serrano, A.; Cortijo, J. Neutrophil Activation in Severe, Early-Onset COPD Patients versus Healthy Non-Smoker Subjects in vitro: Effects of Antioxidant Therapy. Respiration 2012, 83, 147-158. [CrossRef]

158. Kuiper, J.W.P.; Sun, C.; Magalhães, M.A.O.; Glogauer, M. Rac regulates PtdInsP3 signaling and the chemotactic compass through a redox-mediated feedback loop. Blood 2011, 118, 6164-6171. [CrossRef] [PubMed]

159. Nguyen, G.T.; Green, E.R.; Mecsas, J. Neutrophils to the ROScue: Mechanisms of NADPH Oxidase Activation and Bacterial Resistance. Front. Cell. Infect. Microbiol. 2017, 7, 373. [CrossRef]

160. McGuinness, A.J.A.; Sapey, E. Oxidative Stress in COPD: Sources, Markers, and Potential Mechanisms. J. Clin. Med. 2017, 6, 21. [CrossRef]

161. Liu, C.; Wang, F.; Cui, L.; Zhou, J.; Xu, Z. Diagnostic value of serum neutrophil gelatinase-associated lipocalin, interleukin-6 and anti-citrullinated alpha-enolase peptide 1 for lower respiratory tract infections. Clin. Biochem. 2019, 75, 30-34. [CrossRef] [PubMed]

162. Wang, Y.; Jia, M.; Yan, X.; Cao, L.; Barnes, P.J.; Adcock, I.M.; Huang, M.; Yao, X. Increased neutrophil gelatinase-associated lipocalin (NGAL) promotes airway remodelling in chronic obstructive pulmonary disease. Clin. Sci. 2017, 131, 1147-1159. [CrossRef] [PubMed]

163. Gupta, K.; Shukla, M.; Cowland, J.B.; Malemud, C.J.; Haqqi, T. Neutrophil gelatinase-associated lipocalin is expressed in osteoarthritis and forms a complex with matrix metalloproteinase 9. Arthritis Rheum. 2007, 56, 3326-3335. [CrossRef] [PubMed]

164. Tsantikos, E.; Lau, M.; Castelino, C.M.; Maxwell, M.J.; Passey, S.L.; Hansen, M.J.; McGregor, N.E.; Sims, N.; Steinfort, D.; Irving, L.B.; et al. Granulocyte-CSF links destructive inflammation and comorbidities in obstructive lung disease. J. Clin. Investig. 2018, 128, 2406-2418. [CrossRef] [PubMed]

165. Becher, B.; Tugues, S.; Greter, M. GM-CSF: From Growth Factor to Central Mediator of Tissue Inflammation. Immunity 2016, 45, 963-973. [CrossRef]

166. Jasper, A.E.; McIver, W.; Sapey, E.; Walton, G.M. Understanding the role of neutrophils in chronic inflammatory airway disease. F1000Research 2019, 8, 557. [CrossRef]

167. Sundar, I.K.; Yao, H.; Rahman, I. Oxidative Stress and Chromatin Remodeling in Chronic Obstructive Pulmonary Disease and Smoking-Related Diseases. Antioxid. Redox Signal. 2013, 18, 1956-1971. [CrossRef]

168. Aoshiba, K.; Zhou, F.; Tsuji, T.; Nagai, A. DNA damage as a molecular link in the pathogenesis of COPD in smokers. Eur. Respir. J. 2012, 39, 1368-1376. [CrossRef]

169. Sidhaye, V.K.; Nishida, K.; Martinez, F.J. Precision medicine in COPD: Where are we and where do we need to go? Eur. Respir. Rev. 2018, 27, 180022. [CrossRef]

170. Rajendrasozhan, S.; Yang, S.-R.; Edirisinghe, I.; Yao, H.; Adenuga, D.; Rahman, I. Deacetylases and NF- $\mathrm{kB}$ in Redox Regulation of Cigarette Smoke-Induced Lung Inflammation: Epigenetics in Pathogenesis of COPD. Antioxid. Redox Signal. 2008, 10, 799-812. [CrossRef]

171. Caramori, G.; Romagnoli, M.; Casolari, P.; Bellettato, C.; Casoni, G.L.; Boschetto, P.; Chung, K.F.; Barnes, P.J.; Adcock, I.; Ciaccia, A.; et al. Nuclear localisation of p65 in sputum macrophages but not in sputum neutrophils during COPD exacerbations. Thorax 2003, 58, 348-351. [CrossRef]

172. Cosio, B.G.; Tsaprouni, L.; Ito, K.; Jazrawi, E.; Adcock, I.; Barnes, P.J. Theophylline Restores Histone Deacetylase Activity and Steroid Responses in COPD Macrophages. J. Exp. Med. 2004, 200, 689-695. [CrossRef] [PubMed]

173. Barnes, P.J. Role of HDAC2 in the Pathophysiology of COPD. Annu. Rev. Physiol. 2009, 71, 451-464. [CrossRef] [PubMed]

174. Mercado, N.; Thimmulappa, R.; Thomas, C.M.; Fenwick, P.S.; Chana, K.K.; Donnelly, L.; Biswal, S.; Ito, K.; Barnes, P.J. Decreased histone deacetylase 2 impairs Nrf2 activation by oxidative stress. Biochem. Biophys. Res. Commun. 2011, 406, 292-298. [CrossRef] [PubMed]

175. Saco, T.V.; Breitzig, M.T.; Lockey, R.F.; Kolliputi, N. Epigenetics of Mucus Hypersecretion in Chronic Respiratory Diseases. Am. J. Respir. Cell Mol. Biol. 2018, 58, 299-309. [CrossRef]

176. Izzotti, A.; Calin, G.; Arrigo, P.; Steele, V.E.; Croce, C.M.; De Flora, S. Downregulation of microRNA expression in the lungs of rats exposed to cigarette smoke. FASEB J. 2008, 23, 806-812. [CrossRef] [PubMed] 
177. Finicelli, M.; Squillaro, T.; Galderisi, U.; Peluso, G. Micro-RNAs: Crossroads between the Exposure to Environmental Particulate Pollution and the Obstructive Pulmonary Disease. Int. J. Mol. Sci. 2020, 21, 7221. [CrossRef] [PubMed]

178. Omote, N.; Sauler, M. Non-coding RNAs as Regulators of Cellular Senescence in Idiopathic Pulmonary Fibrosis and Chronic Obstructive Pulmonary Disease. Front. Med. 2020, 7. [CrossRef] [PubMed]

179. Cañas, J.A.; Rodrigo-Muñoz, J.M.; Sastre, B.; Gil-Martinez, M.; Redondo, N.; Del Pozo, V. MicroRNAs as Potential Regulators of Immune Response Networks in Asthma and Chronic Obstructive Pulmonary Disease. Front. Immunol. 2021, $11,608666$. [CrossRef] [PubMed]

180. Gon, Y.; Shimizu, T.; Mizumura, K.; Maruoka, S.; Hikichi, M. Molecular techniques for respiratory diseases: MicroRNA and extracellular vesicles. Respirology 2019, 25, 149-160. [CrossRef]

181. Matera, M.G.; Cazzola, M.; Page, C. Prospects for COPD treatment. Curr. Opin. Pharmacol. 2021, 56, 74-84. [CrossRef]

182. Celli, B.; MacNee, W.; Agusti, A.; Anzueto, A.; Berg, B.; Buist, A.; Calverley, P.; Chavannes, N.; Dillard, T.; Fahy, B.; et al. Standards for the diagnosis and treatment of patients with COPD: A summary of the ATS/ERS position paper. Eur. Respir. J. 2004, 23, 932-946. [CrossRef]

183. O'Donnell, D.E. Hyperinflation, Dyspnea, and Exercise Intolerance in Chronic Obstructive Pulmonary Disease; American Thoracic Society: New York, NY, USA, 2006; Volume 3, pp. 180-184.

184. Similowski, T.; Yan, S.; Gauthier, A.P.; Macklem, P.T.; Bellemare, F. Contractile Properties of the Human Diaphragm during Chronic Hyperinflation. New Engl. J. Med. 1991, 325, 917-923. [CrossRef]

185. Garvey, C.; Tiep, B.; Carter, R.; Barnett, M.; Hart, M.; Casaburi, R. Severe Exercise-Induced Hypoxemia. Respir. Care 2012, 57, 1154-1160. [CrossRef] [PubMed]

186. Bodduluri, S.; Reinhardt, J.M.; Hoffman, E.A.; Newell, J.D.; Bhatt, S.P.; John, D.N., Jr. Recent Advances in Computed Tomography Imaging in Chronic Obstructive Pulmonary Disease. Ann. Am. Thorac. Soc. 2018, 15, 281-289. [CrossRef]

187. Decramer, M.; Janssens, W.; Miravitlles, M. Chronic obstructive pulmonary disease. Lancet 2012, 379, 1341-1351. [CrossRef]

188. Beiko, T.; Strange, C. Treatment of Alpha-1 Antitrypsin Deficiency. Semin. Respir. Crit. Care Med. 2015, 36, 470-477. [CrossRef] [PubMed]

189. López-Campos, J.L.; Hernandez, L.C.; Eraso, C.C. Implications of a Change of Paradigm in Alpha1 Antitrypsin Deficiency Augmentation Therapy: From Biochemical to Clinical Efficacy. J. Clin. Med. 2020, 9, 2526. [CrossRef]

190. Malhotra, D.; Thimmulappa, R.K.; Mercado, N.; Ito, K.; Kombairaju, P.; Kumar, S.; Ma, J.; Feller-Kopman, D.; Wise, R.; Barnes, P.; et al. Denitrosylation of HDAC2 by targeting Nrf2 restores glucocorticosteroid sensitivity in macrophages from COPD patients. J. Clin. Investig. 2011, 121, 4289-4302. [CrossRef]

191. Kirkham, P. Oxidative stress and macrophage function: A failure to resolve the inflammatory response. Biochem. Soc. Trans. 2007, 35, 284-287. [CrossRef] [PubMed]

192. Tan, C.; Xuan, L.; Cao, S.; Yu, G.; Hou, Q.; Wang, H. Decreased Histone Deacetylase 2 (HDAC2) in Peripheral Blood Monocytes (PBMCs) of COPD Patients. PLoS ONE 2016, 11, e0147380. [CrossRef]

193. Ito, K.; Ito, M.; Elliott, W.M.; Cosio, B.G.; Caramori, G.; Kon, O.M.; Barczyk, A.; Hayashi, S.; Adcock, I.; Hogg, J.C.; et al. Decreased Histone Deacetylase Activity in Chronic Obstructive Pulmonary Disease. N. Engl. J. Med. 2005, 352, 1967-1976. [CrossRef]

194. Liao, W.; Lim, A.Y.H.; Tan, W.S.D.; Abisheganaden, J.; Wong, W.S.F. Restoration of HDAC2 and Nrf2 by andrographolide overcomes corticosteroid resistance in chronic obstructive pulmonary disease. Br. J. Pharmacol. 2020, 177, 3662-3673. [CrossRef]

195. Izquierdo, J.L.; Cosio, B.G. The dose of inhaled corticosteroids in patients with COPD: When less is better. Int. J. Chronic Obstr. Pulm. Dis. 2018, 13, 3539-3547. [CrossRef]

196. Yawn, B.; Wollan, P.; Rank, M. Exacerbations in the pre- and post-COPD diagnosis periods. Pragmatic Obs. Res. 2013, 4, 1-6. [CrossRef]

197. Restrepo, M.I.; Sibila, O.; Anzueto, A. Pneumonia in Patients with Chronic Obstructive Pulmonary Disease. Tuberc. Respir. Dis. 2018, 81, 187-197. [CrossRef] [PubMed]

198. Biswas, S.; Hwang, J.W.; Kirkham, P.A.; Rahman, I. Pharmacological and Dietary Antioxidant Therapies for Chronic Obstructive Pulmonary Disease. Curr. Med. Chem. 2013, 20, 1496-1530. [CrossRef]

199. Barnes, P.J. Oxidative stress-based therapeutics in COPD. Redox Biol. 2020, 33, 101544. [CrossRef]

200. Menzel, M.; Ramu, S.; Calvén, J.; Olejnicka, B.; Sverrild, A.; Porsbjerg, C.; Tufvesson, E.; Bjermer, L.; Akbarshahi, H.; Uller, L. Oxidative Stress Attenuates TLR3 Responsiveness and Impairs Anti-viral Mechanisms in Bronchial Epithelial Cells From COPD and Asthma Patients. Front. Immunol. 2019, 10. [CrossRef]

201. de Groot, L.; Van Der Veen, T.A.; Martinez, F.O.; Hamann, J.; Lutter, R.; Melgert, B.N. Oxidative stress and macrophages: Driving forces behind exacerbations of asthma and chronic obstructive pulmonary disease? Am. J. Physiol. Cell. Mol. Physiol. 2019, 316, L369-L384. [CrossRef]

202. Dekhuijzen, P.N.R.; Van Beurden, W.J.C. The role for N-acetylcysteine in the management of COPD. Int. J. Chronic Obstr. Pulm. Dis. 2006, 1, 99-106. [CrossRef]

203. Van Antwerpen, P.; Boudjeltia, K.Z.; Babar, S.; Legssyer, I.; Moreau, P.; Moguilevsky, N.; Vanhaeverbeek, M.; Ducobu, J.; Nève, J. Thiol-containing molecules interact with the myeloperoxidase/H2O2/chloride system to inhibit LDL oxidation. Biochem. Biophys. Res. Commun. 2005, 337, 82-88. [CrossRef]

204. Moretti, M. Pharmacology and clinical efficacy of erdosteine in chronic obstructive pulmonary disease. Expert Rev. Respir. Med. 2007, 1, 307-316. [CrossRef] [PubMed] 
205. Rhee, C.K.; Kang, C.M.; You, M.B.; Yoon, H.K.; Kim, Y.K.; Kim, K.H.; Moon, H.S.; Park, S.H.; Song, J.S. Effect of fudosteine on mucin production. Eur. Respir. J. 2008, 32, 1195-1202. [CrossRef] [PubMed]

206. Aggarwal, B.B.; Sundaram, C.; Malani, N.; Ichikawa, H. Curcumin: The indian solid gold. Adv. Exp. Med. Biol. 2007, 595, 1-75. [CrossRef]

207. Suzuki, M.; Betsuyaku, T.; Ito, Y.; Nagai, K.; Odajima, N.; Moriyama, C.; Nasuhara, Y.; Nishimura, M. Curcumin attenuates elastase- and cigarette smoke-induced pulmonary emphysema in mice. Am. J. Physiol. Cell. Mol. Physiol. 2009, 296, L614-L623. [CrossRef] [PubMed]

208. Beijers, R.J.; Gosker, H.R.; Schols, A.M. Resveratrol for patients with chronic obstructive pulmonary disease. Curr. Opin. Clin. Nutr. Metab. Care 2018, 21, 138-144. [CrossRef] [PubMed]

209. Campos, K.K.D.; Ramos, C.D.O.; Martins, T.L.; Costa, G.D.P.; Talvani, A.; Garcia, C.C.M.; Oliveira, L.A.M.; Cangussú, S.D.; Costa, D.C.; Bezerra, F.S. Lycopene mitigates pulmonary emphysema induced by cigarette smoke in a murine model. J. Nutr. Biochem. 2018, 65, 93-100. [CrossRef] [PubMed]

210. Gumus, S.; Yucel, O.; Gamsizkan, M.; Eken, A.; Deniz, O.; Tozkoparan, E.; Genc, O.; Bilgic, H. The role of oxidative stress and effect of alpha-lipoic acid in reexpansion pulmonary edema-An experimental study. Arch. Med Sci. 2010, 6, 848-853. [CrossRef] [PubMed]

211. Oostwoud, L.C.; Gunasinghe, P.; Seow, H.; Ye, J.M.; Selemidis, S.; Bozinovski, S.; Vlahos, R. Apocynin and ebselen reduce influenza A virus-induced lung inflammation in cigarette smoke-exposed mice. Sci. Rep. 2016, 6, 20983. [CrossRef] [PubMed]

212. Wu, T.C.; Huang, Y.C.; Hsu, S.Y.; Wang, Y.C.; Yeh, S.L. Vitamin E and Vitamin C Supplementation in Patients with Chronic Obstructive Pulmonary Disease. Int. J. Vitam. Nutr. Res. 2007, 77, 272-279. [CrossRef] [PubMed]

213. Hesslinger, C.; Strub, A.; Boer, R.; Ulrich, W.-R.; Lehner, M.D.; Braun, C. Inhibition of inducible nitric oxide synthase in respiratory diseases. Biochem. Soc. Trans. 2009, 37, 886-891. [CrossRef]

214. Wang, S.; Lantz, R.C.; Vermeulen, M.W.; Chen, G.J.; Breceda, V.; Robledo, R.F.; Hays, A.M.; Young, S.; Witten, M.L. Functional alterations of alveolar macrophages subjected to smoke exposure and antioxidant lazaroids. Toxicol. Ind. Heal. 1999, 15, 464-469. [CrossRef]

215. Pizzini, A.; Lunger, L.; Sonnweber, T.; Weiss, G.; Tancevski, I. The Role of Omega-3 Fatty Acids in the Setting of Coronary Artery Disease and COPD: A Review. Nutrients 2018, 10, 1864. [CrossRef]

216. Yang, A.; Yu, G.; Wu, Y.; Wang, H. Role of $\beta 2$-adrenergic receptors in chronic obstructive pulmonary disease. Life Sci. 2021, 265, 118864. [CrossRef]

217. Zhai, T.; Li, S.; Hu, W.; Li, D.; Leng, S. Potential Micronutrients and Phytochemicals against the Pathogenesis of Chronic Obstructive Pulmonary Disease and Lung Cancer. Nutrients 2018, 10, 813. [CrossRef]

218. Whyand, T.; Hurst, J.R.; Beckles, M.; Caplin, M.E. Pollution and respiratory disease: Can diet or supplements help? A review. Respir. Res. 2018, 19, 79. [CrossRef] [PubMed]

219. Van Eeden, S.F.; Sin, D.D. Oxidative Stress in Chronic Obstructive Pulmonary Disease: A Lung and Systemic Process. Can. Respir. J. 2013, 20, 27-29. [CrossRef]

220. Malerba, M.; Foci, V.; Patrucco, F.; Pochetti, P.; Nardin, M.; Pelaia, C.; Radaeli, A. Single Inhaler LABA/LAMA for COPD. Front. Pharmacol. 2019, 10. [CrossRef] [PubMed]

221. Kerwin, E.; Stiler, T.M.; Korenblat, P.; White, A.; Eckert, J.H.; Henley, M.; Patalano, F.; D’Andrea, P. Efficacy and Safety of Twice-Daily Glycopyrrolate Versus Placebo in Patients With COPD: The GEM2 Study. Chronic Obstr. Pulm. Dis. J. COPD Found. 2016, 3, 549-559. [CrossRef] [PubMed]

222. Takami, S.; Mizuno, T.; Oyanagi, T.; Tadaki, H.; Suzuki, T.; Muramatsu, K.; Takizawa, T.; Arakawa, H. Glucocorticoids Inhibit MUC5AC Production Induced by Transforming Growth Factor- $\alpha$ in Human Respiratory Cells. Allergol. Int. 2012, 61, 451-459. [CrossRef] [PubMed]

223. Agusti, A.; Fabbri, L.M.; Singh, D.; Vestbo, J.; Celli, B.; Franssen, F.M.; Rabe, K.F.; Papi, A. Inhaled corticosteroids in COPD: Friend or foe? Eur. Respir. J. 2018, 52, 1801219. [CrossRef]

224. Rider, C.; Altonsy, M.O.; Mostafa, M.; Shah, S.V.; Sasse, S.; Manson, M.; Yan, D.; Kärrman-Mårdh, C.; Miller-Larsson, A.; Gerber, A.N.; et al. Long-Acting 32 -Adrenoceptor Agonists Enhance Glucocorticoid Receptor (GR)-Mediated Transcription by Gene-Specific Mechanisms Rather Than Generic Effects via GR. Mol. Pharmacol. 2018, 94, 1031-1046. [CrossRef] [PubMed]

225. Suissa, S.; Dell'Aniello, S.; Ernst, P. Comparative Effects of LAMA-LABA-ICS vs LAMA-LABA for COPD. Chest 2020, 157, 846-855. [CrossRef] [PubMed]

226. Papaioannou, A.I.; Loukides, S.; Bakakos, P.; Kosmas, E.N.; Rovina, N.; Steiropoulos, P.; Fouka, E.; Hillas, G.; Patentalakis, G.; Kouvela, M.; et al. Dual Bronchodilator in the Era of Triple Therapy. Int. J. Chronic Obstr. Pulm. Dis. 2020, 15, $2695-2705$. [CrossRef]

227. Cazzola, M.; Lopez-Campos, J.-L.; Puente-Maestu, L. The MABA approach: A new option to improve bronchodilator therapy. Eur. Respir. J. 2013, 42, 885-887. [CrossRef]

228. Pinho-Ribeiro, V.; Melo, A.C.; Kennedy-Feitosa, E.; Graca-Reis, A.; Barroso, M.V.; Cattani-Cavalieri, I.; Carvalho, G.M.C.; Zin, W.A.; Porto, L.C.; Gitirana, L.B.; et al. Atorvastatin and Simvastatin Promoted Mouse Lung Repair After Cigarette Smoke-Induced Emphysema. Inflammation 2017, 40, 965-979. [CrossRef] [PubMed] 
229. Melo, A.C.; Cattani-Cavalieri, I.; Barroso, M.V.; Quesnot, N.; Gitirana, L.B.; Lanzetti, M.; Valença, S.S. Atorvastatin dosedependently promotes mouse lung repair after emphysema induced by elastase. Biomed. Pharmacother. 2018, 102, 160-168. [CrossRef] [PubMed]

230. Sun, J.; Bao, J.; Shi, Y.; Zhang, B.; Yuan, L.; Li, J.; Zhang, L.; Sun, M.; Zhang, L.; Sun, W. Effect of simvastatin on MMPs and TIMPs in cigarette smoke-induced rat COPD model. Int. J. Chronic Obstr. Pulm. Dis. 2017, 12, 717-724. [CrossRef]

231. Juergens, L.J.; Worth, H.; Juergens, U.R. New Perspectives for Mucolytic, Anti-inflammatory and Adjunctive Therapy with 1,8-Cineole in COPD and Asthma: Review on the New Therapeutic Approach. Adv. Ther. 2020, 37, 1737-1753. [CrossRef]

232. Worth, H.; Schacher, C.; Dethlefsen, U. Concomitant therapy with Cineole (Eucalyptole) reduces exacerbations in COPD: A placebo-controlled double-blind trial. Respir. Res. 2009, 10, 69. [CrossRef]

233. Fischer, J.; Dethlefsen, U. Efficacy of cineole in patients suffering from acute bronchitis: A placebo-controlled double-blind trial. Cough 2013, 9, 25. [CrossRef]

234. Yu, N.; Sun, Y.; Su, X.; He, M.; Dai, B.; Kang, J. Eucalyptol protects lungs against bacterial invasion through attenuating ciliated cell damage and suppressing MUC5AC expression. J. Cell. Physiol. 2019, 234, 5842-5850. [CrossRef]

235. Kennedy-Feitosa, E.; Cattani-Cavalieri, I.; Barroso, M.V.; Romana-Souza, B.; Brito-Gitirana, L.; Valenca, S.S. Eucalyptol promotes lung repair in mice following cigarette smoke-induced emphysema. Phytomedicine 2019, 55, 70-79. [CrossRef]

236. Boo, H.-J.; Park, S.J.; Noh, M.; Min, H.-Y.; Jeong, L.S.; Lee, H.-Y. LJ-2698, an Adenosine A3 Receptor Antagonist, Alleviates Elastase-Induced Pulmonary Emphysema in Mice. Biomol. Ther. 2020, 28, 250-258. [CrossRef] [PubMed]

237. Boo, H.-J.; Park, S.J.; Noh, M.; Min, H.-Y.; Jeong, L.S.; Lee, H.-Y. LJ-529, a partial peroxisome proliferator-activated receptor gamma (PPAR $\gamma$ ) agonist and adenosine A3 receptor agonist, ameliorates elastase-induced pulmonary emphysema in mice. Arch. Pharmacal Res. 2020, 43, 540-552. [CrossRef]

238. Antunes, M.A.; Silva, J.R.L.E.; Rocco, P.R. Mesenchymal stromal cell therapy in COPD: From bench to bedside. Int. J. Chronic Obstr. Pulm. Dis. 2017, 12, 3017-3027. [CrossRef]

239. Mohammadipoor, A.; Antebi, B.; Batchinsky, A.I.; Cancio, L.C. Therapeutic potential of products derived from mesenchymal stem/stromal cells in pulmonary disease. Respir. Res. 2018, 19, 218. [CrossRef] [PubMed]

240. Wang, C.; Zhou, J.; Wang, J.; Li, S.; Fukunaga, A.; Yodoi, J.; Tian, H. Progress in the mechanism and targeted drug therapy for COPD. Signal Transduct. Target. Ther. 2020, 5, 248. [CrossRef] [PubMed]

241. Zhou, J.; Wang, C.; Wu, J.; Fukunaga, A.; Cheng, Z.; Wang, J.; Yamauchi, A.; Yodoi, J.; Tian, H. Anti-Allergic and Anti-Inflammatory Effects and Molecular Mechanisms of Thioredoxin on Respiratory System Diseases. Antioxid. Redox Signal. 2020, 32, 785-801. [CrossRef]

242. Kinoshita, T.; Hoshino, T.; Imaoka, H.; Ichiki, H.; Okamoto, M.; Kawayama, T.; Yodoi, J.; Kato, S.; Aizawa, H. Thioredoxin prevents the development and progression of elastase-induced emphysema. Biochem. Biophys. Res. Commun. 2007, 354, 712-719. [CrossRef]

243. Tanabe, N.; Hoshino, Y.; Marumo, S.; Kiyokawa, H.; Sato, S.; Kinose, D.; Uno, K.; Muro, S.; Hirai, T.; Yodoi, J.; et al. Thioredoxin-1 Protects against Neutrophilic Inflammation and Emphysema Progression in a Mouse Model of Chronic Obstructive Pulmonary Disease Exacerbation. PLoS ONE 2013, 8, e79016. [CrossRef]

244. Blair, H.A. Tiotropium/Olodaterol: A Review in COPD. Drugs 2019, 79, 997-1008. [CrossRef] [PubMed]

245. Babu, K.S.; Morjaria, J.B. Umeclidinium in chronic obstructive pulmonary disease: Latest evidence and place in therapy. Ther. Adv. Chronic Dis. 2017, 8, 81-91. [CrossRef]

246. Rogliani, P.; Calzetta, L.; Ora, J.; Matera, M.G. Canakinumab for the treatment of chronic obstructive pulmonary disease. Pulm. Pharmacol. Ther. 2015, 31, 15-27. [CrossRef] [PubMed]

247. Rennard, S.I.; Fogarty, C.; Kelsen, S.; Long, W.; Ramsdell, J.; Allison, J.; Mahler, D.; Saadeh, C.; Siler, T.; Snell, P.; et al. The Safety and Efficacy of Infliximab in Moderate to Severe Chronic Obstructive Pulmonary Disease. Am. J. Respir. Crit. Care Med. 2007, 175, 926-934. [CrossRef] [PubMed]

248. Mkorombindo, T.; Dransfield, M.T. Mepolizumab in the treatment of eosinophilic chronic obstructive pulmonary disease. Int. J. Chronic Obstr. Pulm. Dis. 2019, 14, 1779-1787. [CrossRef]

249. Janjua, S.; Fortescue, R.; Poole, P. Phosphodiesterase-4 inhibitors for chronic obstructive pulmonary disease. Cochrane Database Syst. Rev. 2020, 5, CD002309. [CrossRef] [PubMed]

250. Martinez, F.J.; Rabe, K.F.; Lipworth, B.J.; Arora, S.; Jenkins, M.; Martin, U.J.; Reisner, C. Glycopyrrolate/Formoterol Fumarate Metered Dose Inhaler Improves Lung Function versus Monotherapies in GOLD Category A Patients with COPD: Pooled Data from the Phase III PINNACLE Studies. Int. J. Chronic Obstr. Pulm. Dis. 2020, 15, 99-106. [CrossRef]

251. Worldometers. COVID-19 Coronavirus Pandemic. 2021. Available online: https://www.worldometers.info/coronavirus/ (accessed on 26 April 2021).

252. Leung, J.M.; Yang, C.X.; Tam, A.; Shaipanich, T.; Hackett, T.-L.; Singhera, G.K.; Dorscheid, D.R.; Sin, D.D. ACE-2 expression in the small airway epithelia of smokers and COPD patients: Implications for COVID-19. Eur. Respir. J. 2020, 55, 2000688. [CrossRef] [PubMed]

253. Alqahtani, J.S.; Oyelade, T.; Aldhahir, A.M.; Alghamdi, S.M.; Almehmadi, M.; Alqahtani, A.S.; Quaderi, S.; Mandal, S.; Hurst, J.R. Prevalence, Severity and Mortality associated with COPD and Smoking in patients with COVID-19: A Rapid Systematic Review and Meta-Analysis. PLoS ONE 2020, 15, e0233147. [CrossRef] [PubMed] 
254. Zhao, Q.; Meng, M.; Kumar, R.; Wu, Y.; Huang, J.; Lian, N.; Deng, Y.; Lin, S. The impact of COPD and smoking history on the severity of COVID-19: A systemic review and meta-analysis. J. Med Virol. 2020, 92, 1915-1921. [CrossRef]

255. Zhou, P.; Yang, X.-L.; Wang, X.-G.; Hu, B.; Zhang, L.; Zhang, W.; Si, H.-R.; Zhu, Y.; Li, B.; Huang, C.-L.; et al. A pneumonia outbreak associated with a new coronavirus of probable bat origin. Nature 2020, 579, 270-273. [CrossRef] [PubMed]

256. Walls, A.C.; Park, Y.-J.; Tortorici, M.A.; Wall, A.; McGuire, A.T.; Veesler, D. Structure, Function, and Antigenicity of the SARS-CoV-2 Spike Glycoprotein. Cell 2020, 181, 281-292.e6. [CrossRef]

257. Higham, A.; Mathioudakis, A.; Vestbo, J.; Singh, D. COVID-19 and COPD: A narrative review of the basic science and clinical outcomes. Eur. Respir. Rev. 2020, 29, 200199. [CrossRef]

258. Toru, U.; Ayada, C.; Genç, O.; Sahin, S.; Arik, Ö.; Bulut, I.; Şahın, S. Serum levels of RAAS components in COPD. Monit. Airw. Dis. 2015, 46. [CrossRef]

259. Higham, A.; Quinn, A.M.; Cançado, J.E.D.; Singh, D. The pathology of small airways disease in COPD: Historical aspects and future directions. Respir. Res. 2019, 20, 49. [CrossRef]

260. Hoffmann, M.; Kleine-Weber, H.; Schroeder, S.; Krüger, N.; Herrler, T.; Erichsen, S.; Schiergens, T.S.; Herrler, G.; Wu, N.-H.; Nitsche, A.; et al. SARS-CoV-2 Cell Entry Depends on ACE2 and TMPRSS2 and Is Blocked by a Clinically Proven Protease Inhibitor. Cell 2020, 181, 271-280.e8. [CrossRef]

261. Sin, D.D. COVID-19 in COPD: A growing concern. EClinicalMedicine 2020, 26, 100546. [CrossRef]

262. Dagens, A.; Sigfrid, L.; Cai, E.; Lipworth, S.; Cheung, V.; Harris, E.; Bannister, P.; Rigby, I.; Horby, P. Scope, quality, and inclusivity of clinical guidelines produced early in the covid-19 pandemic: Rapid review. BMJ 2020, 369, m1936. [CrossRef] [PubMed]

263. Demeyer, H.; Burtin, C.; Hornikx, M.; Camillo, C.A.; Van Remoortel, H.; Langer, D.; Janssens, W.; Troosters, T. The Minimal Important Difference in Physical Activity in Patients with COPD. PLoS ONE 2016, 11, e0154587. [CrossRef] [PubMed]

264. Ambrosino, N.; Bertella, E. Lifestyle interventions in prevention and comprehensive management of COPD. Breathe 2018, 14, 186-194. [CrossRef]

265. Silva, A.R.; Moraes, B.P.T.; Gonçalves-De-Albuquerque, C.F. Mediterranean Diet: Lipids, Inflammation, and Malaria Infection. Int. J. Mol. Sci. 2020, 21, 4489. [CrossRef]

266. Kopsaftis, Z.; Wood-Baker, R.; Poole, P. Influenza vaccine for chronic obstructive pulmonary disease (COPD). Cochrane Database Syst. Rev. 2018, 2018, CD002733. [CrossRef] [PubMed]

267. Froes, F.; Roche, N.; Blasi, F. Pneumococcal vaccination and chronic respiratory diseases. Int. J. Chronic Obstr. Pulm. Dis. 2017, 12, 3457-3468. [CrossRef] 